\title{
Research Paper \\ Comparison of the Effectiveness of Emotion Regulation Training and Mindfulness Training on the Reduction Rumination in the Mothers of Children with Mild Intellectual Disability
}

\author{
Hassan Jafarpour ${ }^{1}$, Bahman Akbari*2 ${ }^{* 2}$ Iraj Shakernia ${ }^{2}$ 3 , Samereh Asadi Mojreh ${ }^{4}$ \\ 1. Ph.D. Student of Department of Psychology, Rasht Branch, Islamic Azad University, Rasht, Iran \\ 2. Associate Professor, Department of Psychology, Rasht Branch, Islamic Azad University, Rasht, Iran \\ 3. Associate Professor, Department of Psychology, Faculty of Literature and Humanities, University of Guilan, Rasht. Iran \\ 4. Assistant Professor, Department of Psychology, Rasht Branch, Islamic Azad University, Rasht, Iran
}

Citation: Jafarpour H, Akbari B, Shakernia I, Asadi Mojreh S. Comparison of the effectiveness of emotion regulation training and mindfulness training on the reduction rumination in the mothers of children with mild intellectual disability. J Child Ment Health. 2021; 7(4): 76-94.

URL: http://childmentalhealth.ir/article-1-1082-en.html
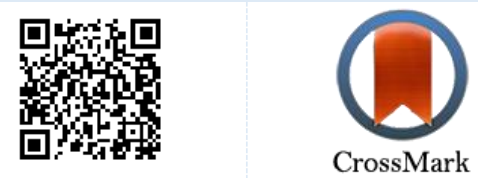

$10.52547 / \mathrm{jcmh} \cdot 7.4 .2$

20.1001.1.24233552.1399.7.4.8.6

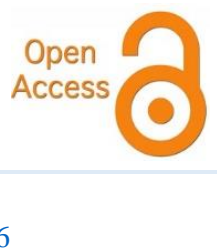

A R T I C L E I N F O

\section{Keywords:}

Intellectual disability, rumination, emotion regulation training, mindfulness training, mothers

Received: 3 Jan 2021

Accepted: 12 Mar 2021

Available: 19 Mar 2021

\section{A B S T R A C T}

Background and Purpose: Children with intellectual disability may cause growing psychological problems for their parents, specifically the mothers as the principal caregivers. During the recent years, different research and clinical methods have been used to reduce these psychological problems. Present research was conducted to compare the effectiveness of emotion regulation training and mindfulness training on the reduction of rumination in the mothers of children with mild intellectual disability.

Method: This study was a quasi-experimental research with multi-group pretest-posttest design. The population included all the mothers of children with mild intellectual disability who had referred to the special schools of Rasht in the academic year 2019-2020. Among them, a sample of 36 mothers was selected by purposive sampling and then randomly assigned into the experimental or control groups (12 mothers per group). To collect the data, Ruminative Response Scale (Nolen-Hoeksema \& Morrow, 1991) was used. After nine 90-min sessions of emotion regulation training and mindfulness training conducted for the experimental groups, all the three groups were reassessed at the post-test stage. Data were analyzed by one-way ANCOVA and multivariate ANCOVA in SPSS22.

Results: Data analysis showed that emotion regulation training and mindfulness training significantly decreased the overall rumination and its components in the mothers of children with mild intellectual disability $(\mathrm{P}<0.01)$. Furthermore, based on the results of post hoc tests, it can be said that there was no significant difference between emotion regulation training and mindfulness training in reducing the overall rumination and its components $(\mathrm{P}>0.05)$.

Conclusion: Based on these findings, it can be said that emotion regulation by improving the emotional repair, reducing the negative self-referential processing, and increasing the ability of doing purposive behaviors, and mindfulness training by increasing the present moment awareness and more efficient information processing are effective in reducing rumination in the mothers of children with mild intellectual disability.

* Corresponding author: Bahman Akbari, Associate Professor, Department of Psychology, Rasht Branch, Islamic Azad University, Rasht, Iran. E-mail: Bakbari44@yahoo.com

Tel: (+98) 1333423308

2476-5740/ (C) 2021 The Authors. This is an open access article under the CC BY-NC-ND license

(https://creativecommons.org/licenses/by-nc-nd/4.0/). 


\section{Quarterly Journal of}

Child Mental Health

\section{Extended Abstract}

\section{Introduction}

During the recent decades, more and more children with special needs have been found (1). One of these groups are children with intellectual disability, i.e. an intellectual-developmental disorder identified by deficiency in mental function and adaptive behavior in the conceptual, social and practical scopes, where based on the severity of the failure in the adaptive function, the individual is included in one of the mild, moderate, sever, or profound categories (2). Alongside, research shows that children with intellectual disability may cause numerous mental health problems for the family members, especially the mothers (7). Findings indicate the higher levels of stress, psychological distress, depression, and health problems in the parents of these children (3-5) as well as higher level of depression and anxiety in the mothers of children with intellectual disability (8). Meanwhile, rumination is an important variable noticed in mothers of children with special needs (12\&13). Lewis, Yoon, and Joorman (15) consider rumination as the interpretation of the stressful events of life and identify it as the rumination of responding to stress. Therefore, rumination is one of the problems evident in the mothers of children with special needs, specifically intellectual disability, and it needs growing attention. (12)

One of the mechanisms suggested for reducing the cognitive, behavioral, and psychological problems in the mothers of children with special need, is emotion regulation training. $(23,24, \& 28)$ Emotion regulation training contains strategies that influence the emotions through limiting the time, place and situation of their occurrence and includes both the positive and negative emotions (20). Numerous researches indicate the effectiveness of emotion regulation training on the reduction of negative affect and increase of resiliency in the mothers of children with disability (24), increase of psychological well-being in the mothers of students with intellectual disability (27) and reduction of rumination (29 \& 31).

Another therapy used for the parents of children with special needs, is mindfulness training (32). Mindfulness intervention relies on meditation techniques like body scan to increase our awareness of the way the thoughts work. This technique tries to improve non-judgmental awareness in the present moment, attention to the present moment and nonreactive acceptance of thoughts and feelings (33). Research indicates that applying mindfulness-based interventions for the parents of children with special needs have brought about positive results, especially for the mothers (3\&5). In fact, mindfulness training is effective in reducing depression and increasing life expectancy in the mothers of children with intellectual disability (43), reducing the level of stress in the mothers of children with intellectual disability (45) and increasing the sociability and quality of life in the parents of children with intellectual disability (32). Although some studies have investigated the effectiveness of emotion regulation training and mindfulness-based training programs on the reduction of psychological problems in the mothers of children with intellectual disability, a research gap exists in comparing the effectiveness of the said interventions on the dependent variable of the present research, which requires further study. Therefore, present research was conducted to compare the effectiveness of emotion regulation training and mindfulness training on the reduction of rumination in the mothers of children with intellectual disability.

\section{Method}

This study was a quasi-experimental research with multi-group pretest-posttest design. The population included all the mothers of children with mild intellectual disability who had referred to the special schools of Rasht in the academic year 2019-2020. Among them, a sample of 36 mothers was selected by purposive sampling and then randomly assigned into the experimental or control groups (12 mothers per group). To collect the data, Ruminative Response Scale (Nolen-Hoeksema \& Morrow, 1991) was used. Emotion regulation training program used in this study was based on Gross's model for emotion regulation (51). Also, Kabat-Zinn Mindfulnessbased Stress Reduction (MBSR) was used in this study (33). After selecting the sample and assigning them to the groups, the participants, being explained the research purposes, were asked to take part in the study. At the beginning, all the three groups completed the rumination scale. Then, the first and second experimental groups received the emotion regulation training and mindfulness training, respectively; while the control group underwent no intervention. Both programs included eight 90-min training sessions which were convened by the first author in the special schools of Rasht (Guilan province). Upon the completion of the training 
sessions, all the three groups were assessed at the post-test stage. Data were analyzed by one-way ANCOVA and multivariate ANCOVA in SPSS-22.

\section{Results}

Table 1 shows the mean and standard deviation scores of rumination and its components for the experimental and control groups at the pretest and posttest phases. Findings implied that the mean score of rumination and its components for both experimental groups decreased at the posttest stage. To investigate the effectiveness of emotion regulation training and mindfulness training on the overall rumination and its components, one way ANCOVA was used (it is worth mentioning that the assumptions were tested and they were not significant at $\mathrm{p}=0.05)$.

Table 1: Descriptive statistics of rumination and its components as per the experimental and control groups

\begin{tabular}{|c|c|c|c|c|c|c|c|}
\hline \multirow{2}{*}{ Variable } & \multirow{2}{*}{ Phase } & \multicolumn{2}{|c|}{ Emotion regulation training } & \multicolumn{2}{|c|}{ Mindfulness training } & \multicolumn{2}{|c|}{ Control group } \\
\hline & & Mean & SD & Mean & SD & Mean & SD \\
\hline \multirow{2}{*}{ Overall rumination } & Pre-test & 53.417 & 3.919 & 54.167 & 3.486 & 54.417 & 4.621 \\
\hline & Post-test & 33.250 & 5.926 & 34.417 & 5.946 & 53.500 & 6.599 \\
\hline \multirow{2}{*}{ Symptom-based rumination } & Pre-test & 21.583 & 1.240 & 21.667 & 1.497 & 22.833 & 1.946 \\
\hline & Post-test & 14.167 & 3.128 & 15.417 & 3.476 & 22.417 & 4.738 \\
\hline \multirow{2}{*}{ Introspection } & Pre-test & 12.500 & 1.168 & 13.750 & 1.545 & 13.333 & 1.969 \\
\hline & Post-test & 6.250 & 1.357 & 7 & 1.595 & 12.667 & 2.964 \\
\hline \multirow{2}{*}{ Self-blame } & Pre-test & 19.333 & 2.498 & 18.750 & 1.913 & 18.250 & 2.094 \\
\hline & Post-test & 12.833 & 3.214 & 12 & 2.594 & 18.417 & 4.209 \\
\hline
\end{tabular}

Table 2: Results of one-way ANCOVA for explaining the inter-group difference of overall rumination

\begin{tabular}{|c|c|c|c|c|c|c|c|c|}
\hline \multirow[b]{2}{*}{ Source } & \multirow[b]{2}{*}{ SS } & \multirow[b]{2}{*}{ df } & \multirow[b]{2}{*}{ MS } & \multirow[b]{2}{*}{$\mathbf{F}$} & \multirow[b]{2}{*}{$\mathbf{p}$} & \multicolumn{3}{|c|}{ Bonferroni pairwise comparison } \\
\hline & & & & & & $\begin{array}{c}\text { Emotion regulation } \\
\text { training and mindfulness } \\
\text { training }\end{array}$ & $\begin{array}{c}\text { Emotion regulation } \\
\text { training and control } \\
\text { group } \\
\end{array}$ & $\begin{array}{l}\text { Mindfulness } \\
\text { training and } \\
\text { control group }\end{array}$ \\
\hline $\begin{array}{l}\text { Corrected } \\
\text { pattern }\end{array}$ & 3114.721 & 3 & 1038.240 & 26.754 & 0.000 & & & \\
\hline Pre-test & 12.332 & 1 & 12.322 & 0.318 & 0.577 & 1 & 0.000 & 0.000 \\
\hline Group & 3051.808 & 2 & 1525.904 & 39.320 & 0.000 & & & \\
\hline Error & 1241.834 & 32 & 38.807 & & & & & \\
\hline
\end{tabular}

Table 2 shows that there was a significant difference between the groups in terms of overall rumination $(\mathrm{P}=0.00, \mathrm{~F}=39.320)$. To investigate the effect of emotion regulation training and mindfulness training on the components of rumination, multivariate ANCOVA was used (assumptions were not significant at $\mathrm{p}=0.05$ ). Results of Wilk's lambada to determine the overall effect on the components of rumination showed that the overall effect was significant $(\mathrm{p}<0.001)$.

Table 3: Results of multivariate ANCOVA for explaining the inter-group difference of the components of rumination

\begin{tabular}{|c|c|c|c|c|c|c|c|c|c|}
\hline \multirow{2}{*}{\multicolumn{2}{|c|}{$\begin{array}{l}\text { Components of } \\
\text { rumination }\end{array}$}} & \multirow[b]{2}{*}{ SS } & \multirow[b]{2}{*}{ df } & \multirow[b]{2}{*}{ MS } & \multirow[b]{2}{*}{$\mathbf{F}$} & \multirow[b]{2}{*}{$\mathbf{p}$} & \multicolumn{3}{|c|}{ Bonferroni pairwise comparison } \\
\hline & & & & & & & $\begin{array}{l}\text { Emotion regulation } \\
\text { training and } \\
\text { mindfulness training }\end{array}$ & $\begin{array}{c}\text { Emotion } \\
\text { regulation } \\
\text { training and } \\
\text { control group }\end{array}$ & $\begin{array}{l}\text { Mindfulness } \\
\text { training and control } \\
\text { group }\end{array}$ \\
\hline \multirow[t]{3}{*}{ Group } & $\begin{array}{l}\text { Symptom- } \\
\text { based } \\
\text { rumination }\end{array}$ & 322.783 & 2 & 161.392 & 10.308 & 0.000 & 1 & 0.001 & 0.003 \\
\hline & Introspection & 244.314 & 2 & 122.157 & 28.643 & 0.000 & 1 & 0.000 & 0.000 \\
\hline & Self-blame & 364.961 & 2 & 123.792 & 10.176 & 0.000 & 1 & 0.006 & 0.000 \\
\hline
\end{tabular}

Table 3 shows that the groups were significantly different in the symptom-based rumination $(\mathrm{F}=10.308$, $\mathrm{p}=0.000)$, introspection $(\mathrm{F}=28.643, \mathrm{p}=0.000)$ and selfblame $(\mathrm{F}=10.176, \mathrm{p}=0.000)$. Also, results of Benferroni pairwise comparison indicated that both interventions were equally effective on the components of rumination and that there was no significant difference between them $(\mathrm{p}<0.001)$. 


\section{Conclusion}

This study was conducted to determine and compare the effectiveness of emotion regulation training and mindfulness training on the reduction of rumination in the mothers of children with mild intellectual disability. Findings show that emotion regulation training reduced rumination and its components. Results of this study coincide with those of Karami et al. (31), indicating the effectiveness of Gross's model for emotion regulation on the reduction of rumination, and Moradikia et al. (27), indicating the effectiveness of emotion regulation on the increase of psychological well-being of mothers of students with intellectual disability. To explain this finding, Du, Huang, An, \& Xu (17) argue that negative emotions are associated with rumination. Therefore, assessment of the emotions prior to their formation, not only helps stopping the exaggerated emotions at the time of confronting with a negative emotional situation, but also prevents a significant reduction of happiness after the stressful event and reduces the ruminative thinking in the individual (18). By strategies like emotional response adjustment, situation modification, attention deployment, and cognitive changes, emotion regulation training can increase affective regulation and decrease inefficient thoughts, including ruminative thinking. Therefore, by improving capabilities like focused attention and selfmonitoring, emotion regulation may be effective in reducing rumination in the mothers of children with intellectual disability (19).

Also, results showed that mindfulness training reduces rumination and its components. Similarly, previous researches indicate that mindfulness-based intervention can be effective in reducing the psychological problems and increasing the quality of life in the parents of children with intellectual disability $(3,5,32,43, \& 45)$. Aghdasi, Soleimanian, \& Asadi Gandomani (42) showed that mindfulness training reduces the emotional schema, including rumination, feeling guilty, and not expressing the feelings in the mothers of children with cerebral palsy. Tumminia et al (40) found that mindfulness training results in the reduction of ruminative response. Also, Moriera and Canavarro (12) showed that mindful parenting reduces rumination and stress in parents. To explain this, it can be said that mothers of children with special needs are more susceptible to emotional tensions like stress, anxiety, and depression, which in turn activates emotional schema like rumination and feeling guilty. Therefore, through regulating the attention, developing the metacognitive awareness, decentralization and accepting mental content, mindfulness can be effective in reducing maladaptive emotional schema, especially rumination (42). So, the components of mindfulness, especially nonjudgmental acceptance are effective in reducing rumination (40).

Finally, to explain this fact that no difference was found between emotion regulation training and mindfulness training, it can be said that by trigging the related brain functions, emotion regulation training can result in the improvement of self-regulation and reduction of inefficient emotions like rumination (40). Similarly, by making neurological changes in the frontal part of the brain, mindfulness training results in the reduction of rumination through increasing the self-regulation and attention capacity (4). Therefore, both techniques work on the basis of similar brain structures and the principle of self-regulation, wherein feelings and behaviors are controlled cognitively and emotionally. The impossibility to perform the follow-up phase was one of the limitations of this research. Finally, it is suggested to simultaneously use emotion regulation training and mindfulness training to reduce psychological problems- especially ruminationin the mothers of children with intellectual disability.

\section{Ethical Considerations}

Compliance with the ethical guidelines: This article is extracted from the Ph.D. dissertation of the first author, which was approved under No. 1399009 in the field of General Psychology at Rasht Branch of Islamic Azad University and was defended in 2020. The permission for carrying it out was issued by Rasht Education Administration of Special Schools in 2019. Other ethical considerations like gaining the informed consent of the participants and the confidentiality were also observed in this research.

Funding: This study, extracted from the Ph.D. dissertation, was conducted without the financial support of any institute or organization.

Author's Contribution: The first author, Mr. Hassan Jafarpour, was the principal researcher who proposed the research and collected the data. The second author was the the supervisors, and the fourth and fifth ones were the advisors.

Conflict of interests: There is no conflict of interest in this study.

Acknowledgments: We would like to appreciate the authorities of special schools in Rasht as well as the mothers participating in this research. 


\title{
مقايسه اثربخشى آموزش تنظيم هيجان و ذهن آكاهى بر بهبود نشخوار فكرى مادران دار اى كودكان كمتوان ذهنى خفيف
}

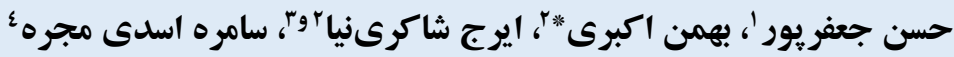

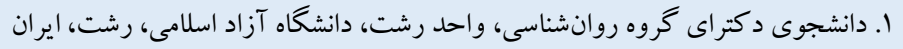

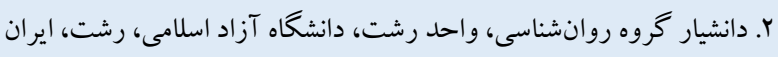

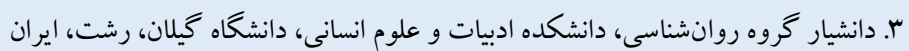

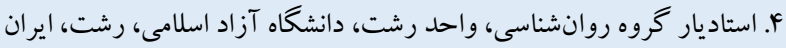

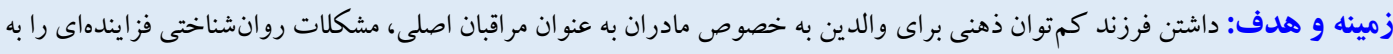

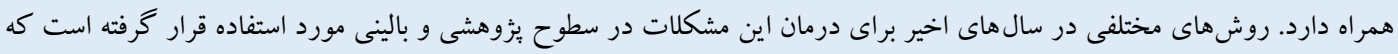

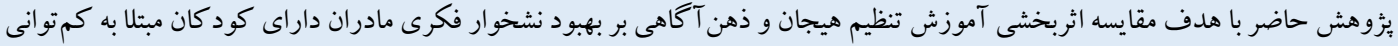
ذهنى خفيف انجام شد.

جكيu

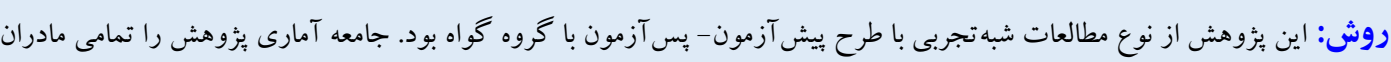
داراى كودكك مبتلا به كمتوانى ذهنى خفيف مر اجعه كننده به مدارس استثنايى شهر رشت در سال تحصيلى

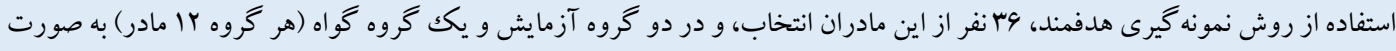

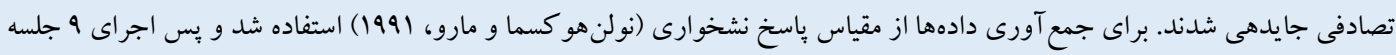

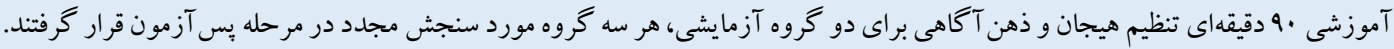

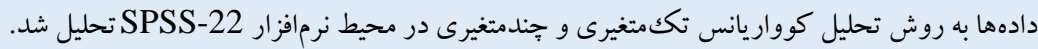

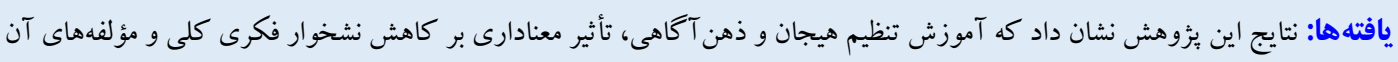

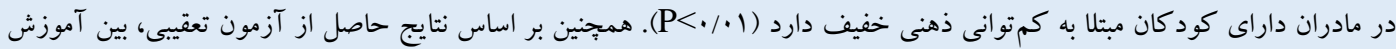

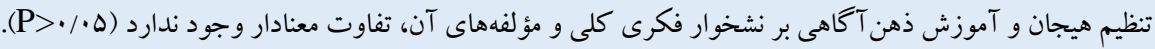

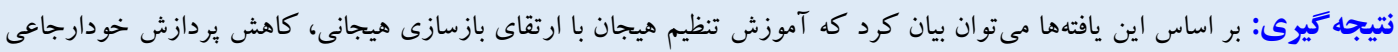

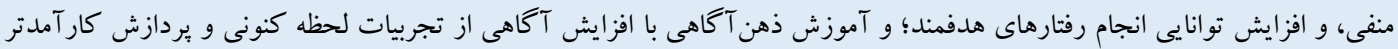

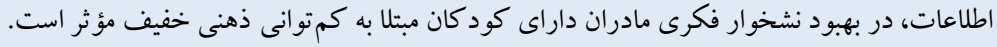

مشخصات مقاله

كليدواخهها:

كم توانى ذهنى،

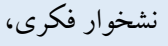

آموزش تنظيم هيجان،

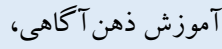

مادران

دريافت شده: 99/1//F

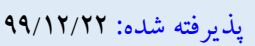
منتشر شده: M9/IY/Y9

* نويسنده مسئول: بهمن اكبرى، دانشيار گروه روانشناسى، واحد رشت، دانشكاه آزاد اسلامى، رشت، ايران.

رايانامه: Bakbari44@yahoo.com 
داشــتن يـك كود كك بـا نيازهاى ويثهه و ابتلا به اختلالات روانشـــناختى مر تبط با نشخوار فكرى ؟ را تأييد مى كنند. نشخوار فكرى يكى از متغيرهاى قابل توجه در مادران داراى فرزند با

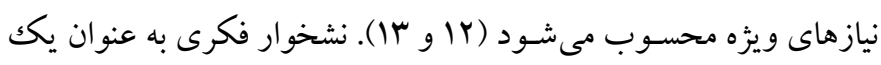
حالت ياســخ تعريف مىشـود كه در آن افراد به طور مكرر و منفعلانه بر علائم يريشـانى، دلايل و نتايج احتمالى اين علائم تمركز مى كنند (IF). لويز، يون، و جورمن (ها) نيز نشــخوار فكرى رابه عنوان تعبير و تفسـير حو ادث تنش آور زنـدگى مى دانند و واكنشى به تنيدگى معرفى مى كنند. بر طبق تعـاريف ذكر شــده، نشــخوار فكرى افكارى هســتـند كه: () به حوادث يا ماهيت خلق افسرده مـــربوط هستند، Y) هدف مدار نـــبوده و افـــراد را به طرح و عمل خاصى راهنمايى نمى كنند، و r) زمانى كه فرد دركير نشخوار فكرى است از لحـــاظ اجـــماعى بـــا محيط همخوانى و مشــاركت ندارد (19). نشـــوار فكرى يكى از مشـكلات بارز جمعيت مادران داراى فرزند با نيازهاى ويزٔه به خصسوص مادران داراى فرزند مبتلا به كم توانى ذهنى است كه توجه فزايندهاى را مى طلبد (Y) (I). يثزوهش ها راهكارهاى متفاوتى را جهت بهبود مشـكلات شــناختى، رفتارى، و روانشـناختى والدين كود كان با نيازهاى ويزه ارائه دادهاندكه يكى از اين روشهـاى مؤثر، آموزش تنظيم هيجـان بـ اســـت (IV-19). آموزش تنظيم هيجـان شـامل آموزش راهبردهايى اســت كه منجر به تأثير گذارى بر هيجانات از طريق محدود كردن زمان، مكان، و موقعيت بروز آنها اسـت كه شـامل تنظيم هر دو هيجانات مثبت و منفى مىشــود

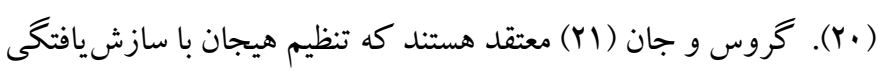
و تعـاملات اجتماعى مثبت مرتبط اسـتـت و افزايش در فراوانى تجربههاى هيجانى مثبت باعث سـازش يافتخى مؤثر با موقعيت هاى تنش آور مى شود و حتى فعاليت هاى للازم در ياســـخ به موقعيتهاى اجتماعى را بالا مىبرد. همجينين بثزوهشخران معتقدند تنظيم هيجان، به عنوان توانايى تأثير خذارى بر تجربه و ابراز هيجانات فرد، مهارتى ييجيده اســت كه در طول زندكى

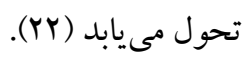

يثزوهش هاى متعدد نشـاندهنده اثرات مثبت آموزش تنظيم هيجان بر بهبود متغيرهاى مختلف روانشناختى در نمونه والدين كود كان با نيازهاى

3. Emotional regulation training
مقلهم

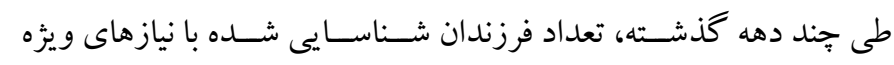

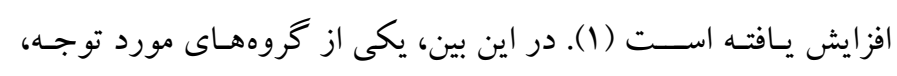

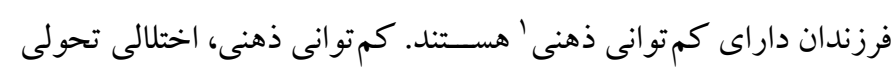
اسـت كه به واســطه نارســايى در كاركرد ذهنى و رفتار ســازشـى در حوزههاى مغهومى، اجتماعى، و عملى تعريف مى شـود. با توجه به شدت آســبـ در كار كرد سـازشسى، فرد در طيف خفيف، متوسـط، شــديد، و

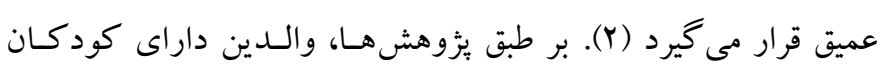
كمتوان ذهنى اغلب در مقايسه با والدين كود كان بهنجار، به دليل افزايش

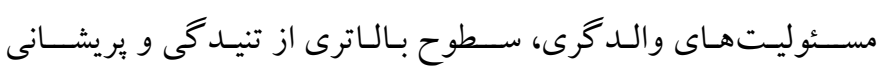
روانشــــاختى را تجربـه مى كنند (ب و \&)؛ به طورى كه والدين كود كان كم توان ذهنى دو بر ابر ساير والدين، دجار تنيدگى، افسردگى و مشكلات

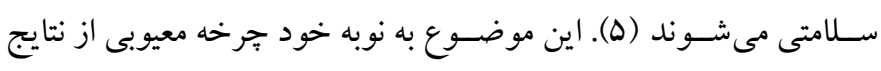
منفى براى اين كود كان و بهزيستى خانو اده منجر به مىشود (4). كودكك كمتوان ذهنى مشـكلات بسـيارى را در زمينه سـلامت روان براى اعضـاى خانواده بهويزه مادر ايجاد مى كند (V). بر طبق بزوهشها، افســردكى و اضــطر اب مادران داراى كودكى كم توان ذهنى از مادران داراى كودكك بهنجار بيشـتر اسـت (N). همجينين در يزٔوهشى ديخر نشان داده شـــــــه مـادران داراى كود كـان با كم توانى ذهنى، در مقايســـه با يدران، اضطر اب، افسردگى و تنيدگى بيشترى را تجربه مى كنند (9). در اين راستا، لى در يُزوهشى نشان داد مادرانى كه داراى فرزندان با كم توانى تحولى هستيند، سطوح بالاترى از تنيدگى را نسبت به ديخر مادران تجربه

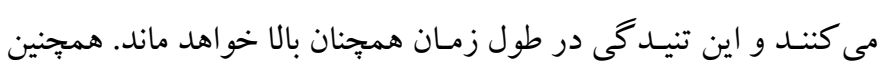
اين تنيدگى از منابع مختلفى سر جشمه مى گيرد كه ممكن است مربوط به

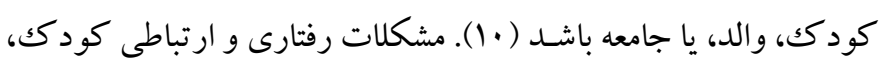

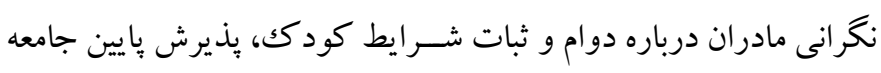
و حتى سـاير اعضـاى خانواده نسـبت به رفتارهاى كود كى، حمايتهاى اجتماعى كم، مشكلات مالى، انزوا و كمبود آكاهى والدين درباره تحول

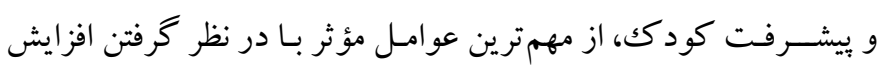
تنش هاى والدكرى در آنها است (1) (1). اين يافتهاى ئزوهشى ارتباط بين

1. Mental disabilities

2. Rumination 


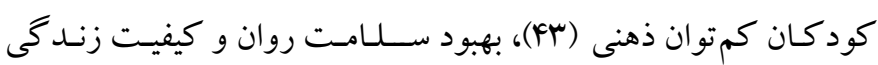

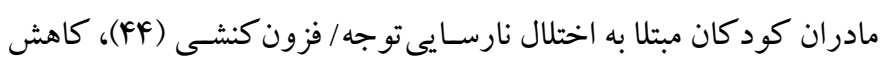

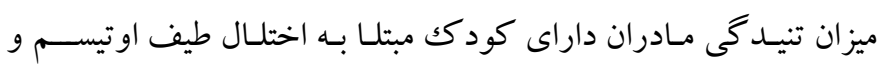

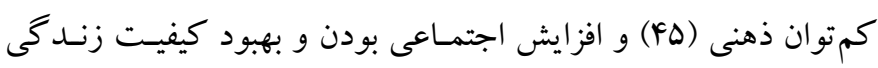

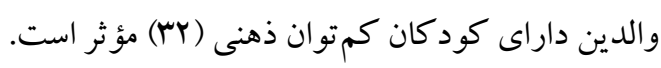

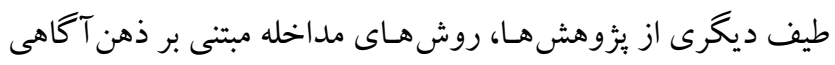

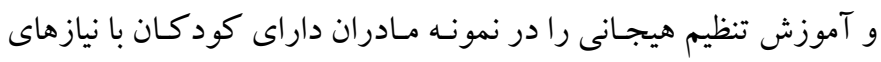

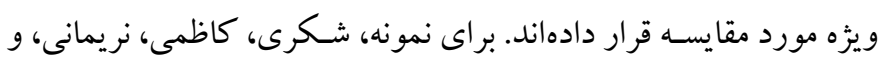

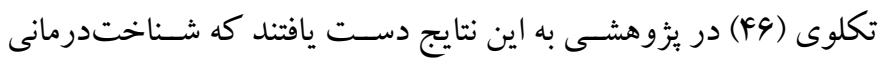

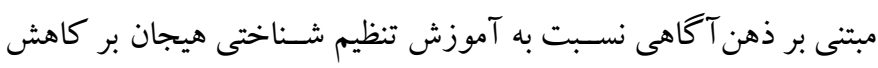

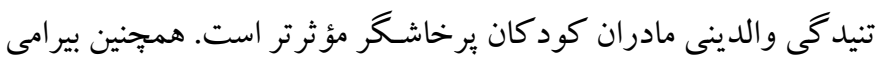

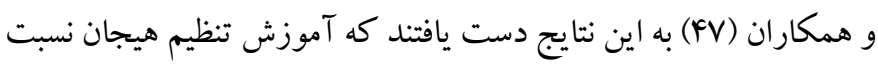

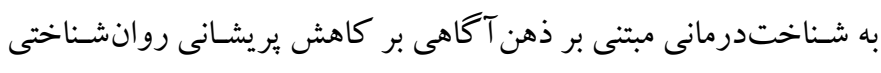

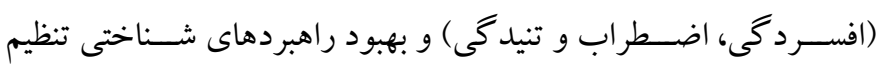

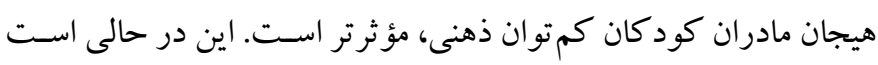

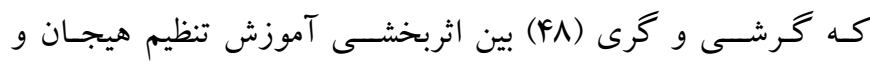
ذهن آكتاهى بر كاهش خشــونت والدين داراى كودكان مبتلا به اختلال نارسايى تو جه / فزون كنشى، تفاوتى را مشاهده نكردند

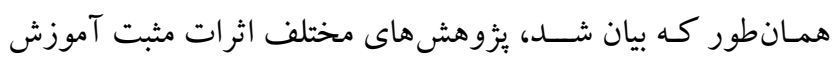
تنظيم هيجان و ذهن آكاهى را بر طيف گســتردهاى از متغيرها در والدين

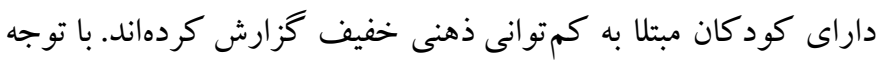

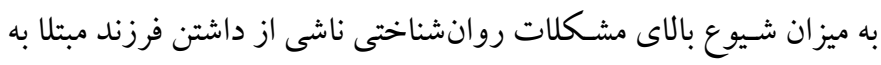

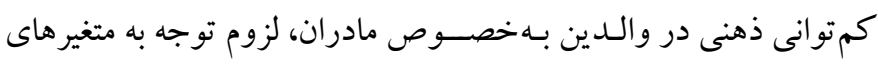

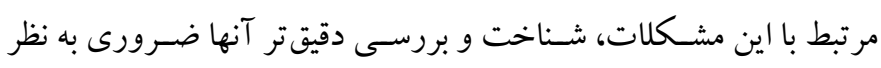
مىرسد تا روشهاى مختلف آموزشى به كار گرفته شده براى اين مادران

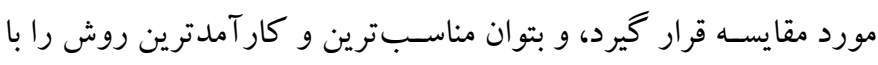

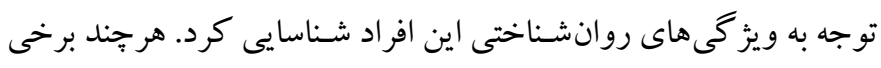

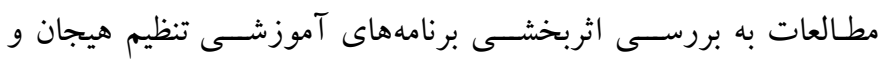

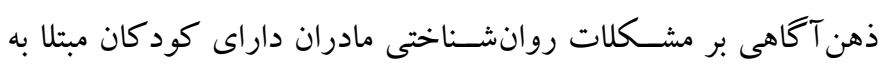

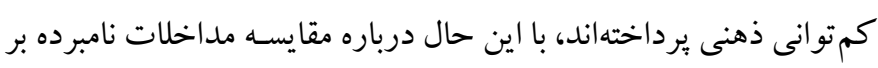

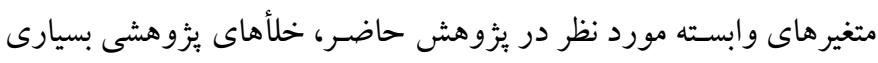

ويزه اسـت. يافتهاى اين يزٔوهشها نشـانغر اثربخشـى آموزش تنظيم

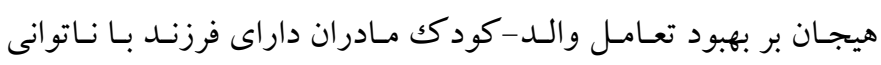

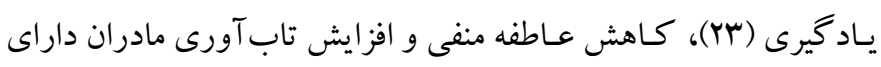

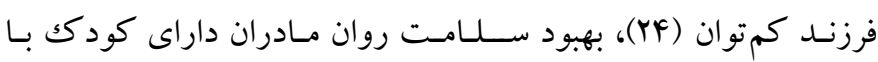

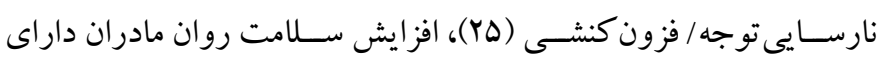

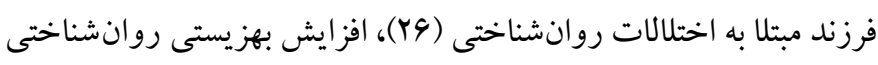

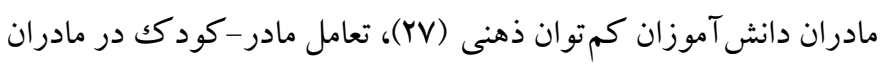

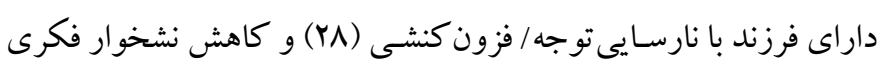

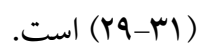
از ديخر درمانهاى مورد استفاده در نمونه والدين كود كان با نيازهاى

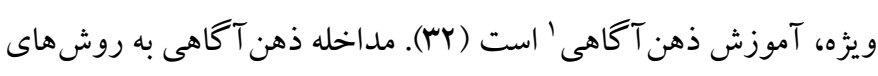

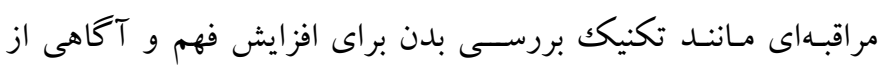

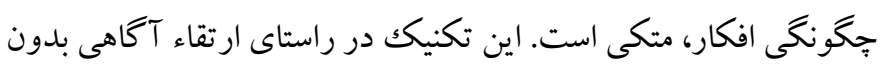

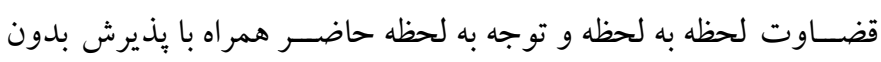

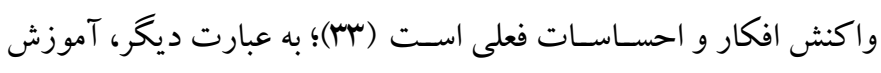

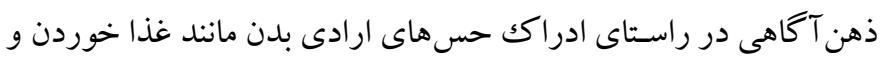

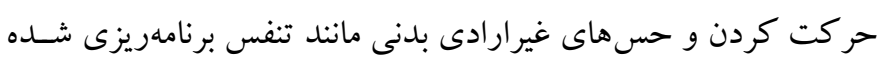

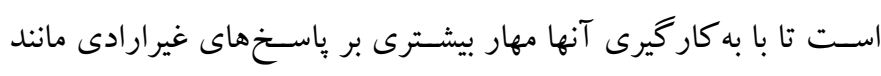

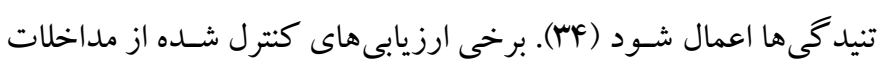
مبتنى بر ذهن آكاهى در والدين داراى كود كان كمتو توانى ذهنى به به نتايج مثبتى به خصوص براى مادران منجر شده است (ب و ه ه).

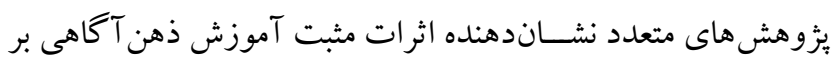

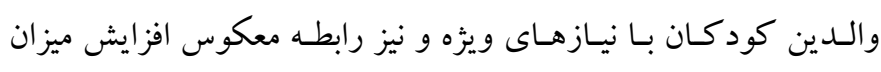

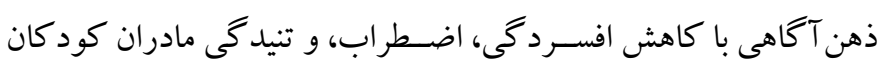

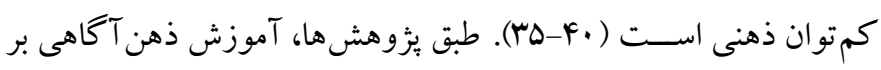

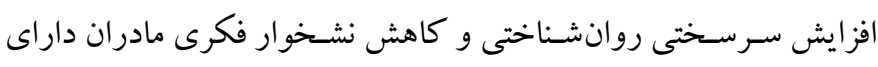

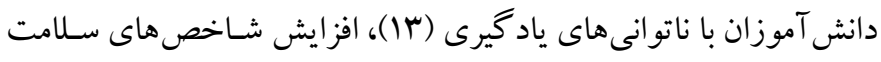

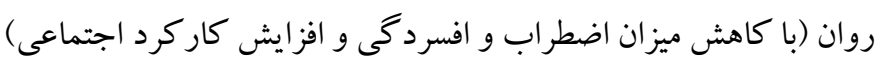

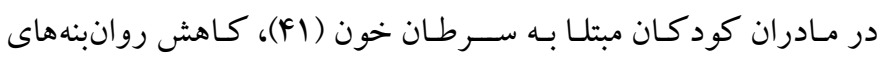

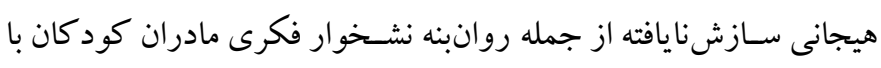

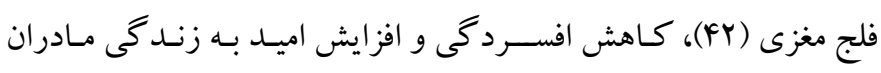


و يـا آموزش ذهن آكاهى حداقل يكك سـال قبل از اجراى مطالعه، عدم

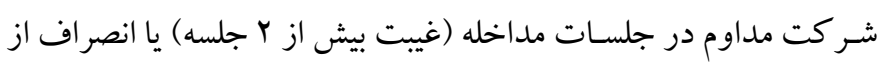

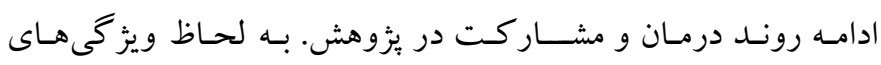

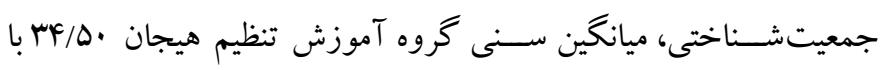

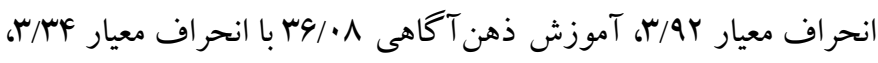

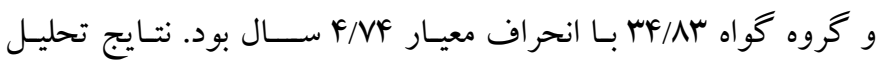

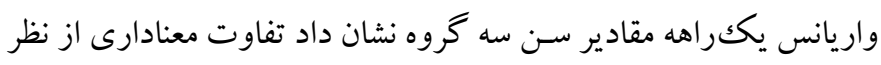

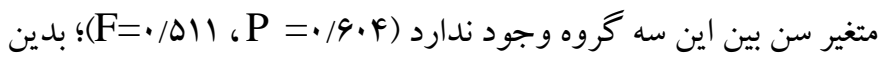
مفهوم كه اين سه گروه از نظر متغير سن همتا هستند.

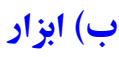
مقياس باستخ نشـوارى ': اين ابزار، زيرمقياسى از يرسشنامه سبكك هاى

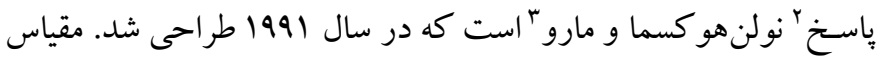

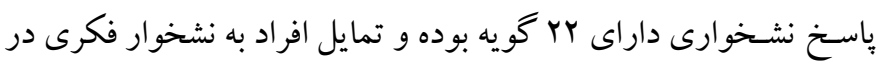

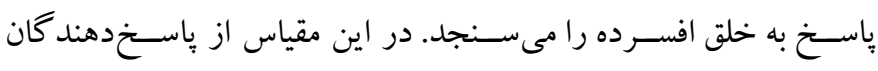

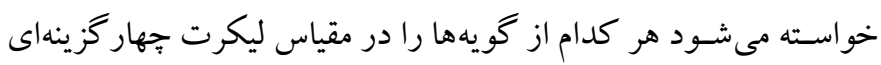

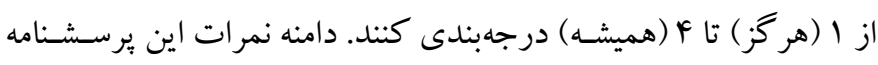

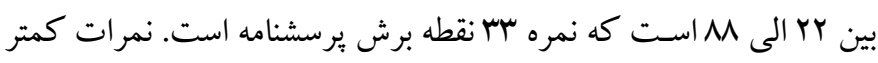

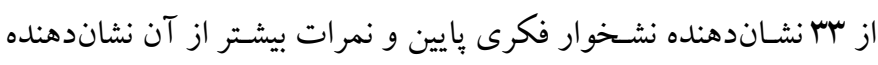

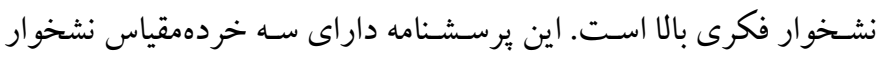

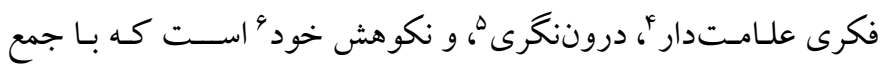

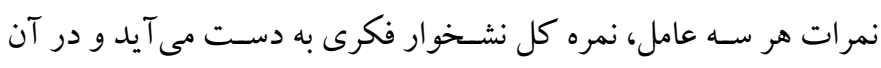

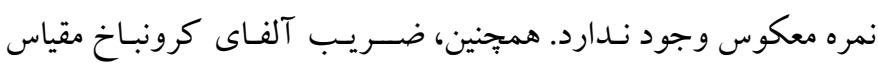

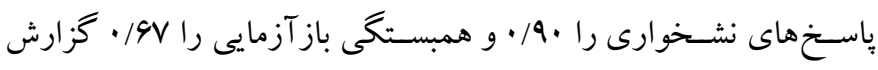

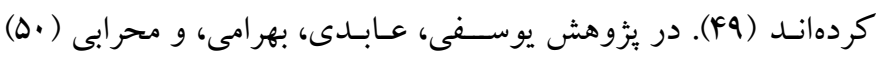

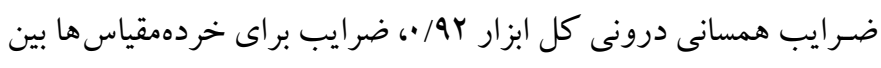

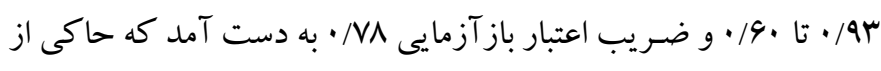
اعتبار و همسانى درونى بالاى اين برسشنامه است. همجنين ضريب روبي روايى

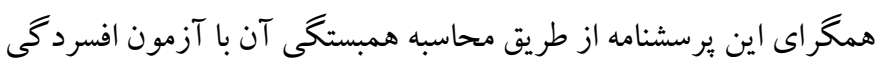

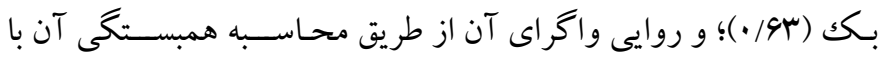

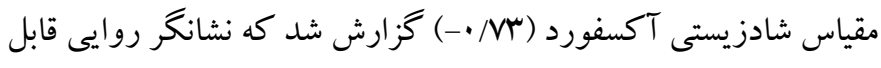

4. Symptom-based

5. Introspection

6. Self-balame
وجود دارد كه انجام مطالعات بيشستر را ضسرورى مىسـازد. از اين رو،

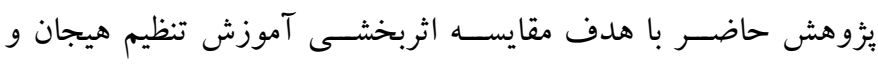

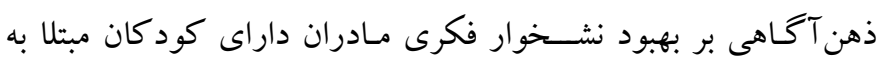
كم توانى ذهنى خفيف انجام شد.

روش

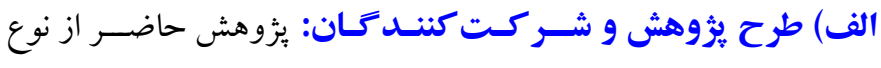

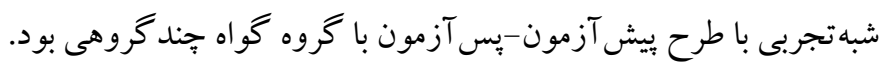

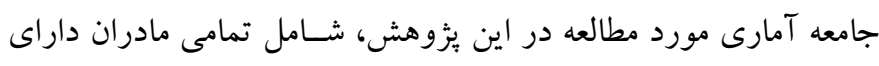

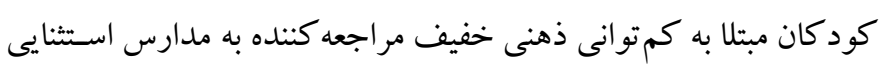

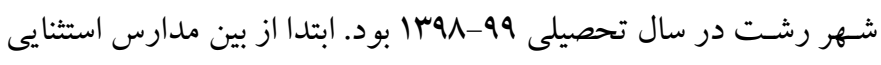
شهر رشـ، جهار مدرسـه به صـورت در دسـترس انتخاب شـــ (در اين

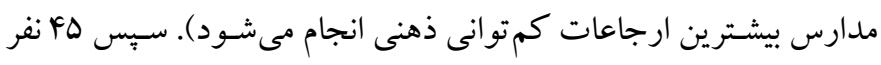

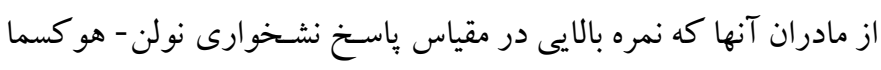

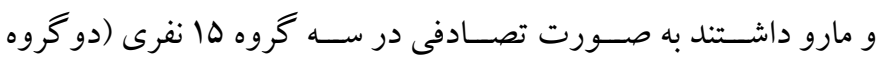

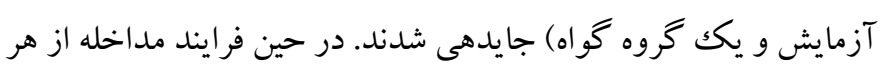

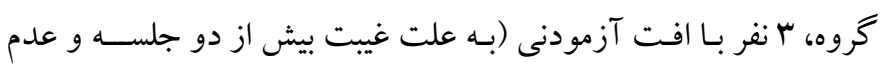

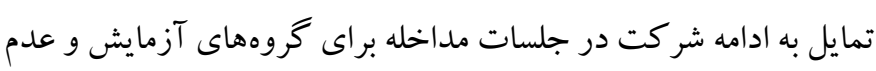

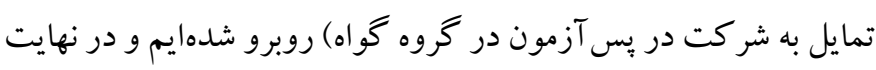

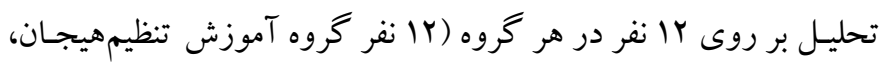

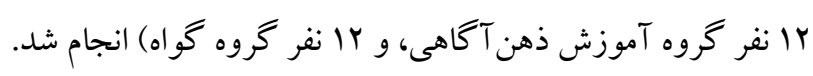

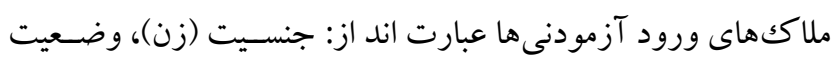

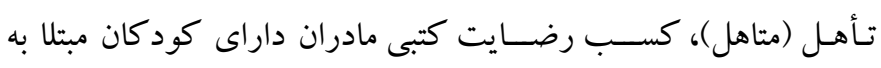

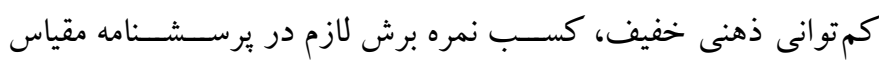

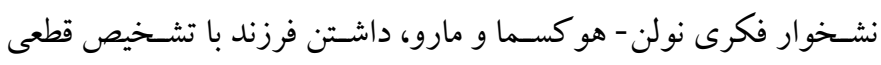

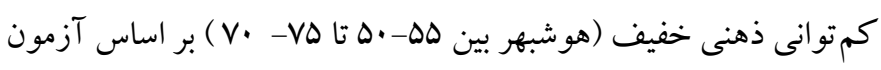

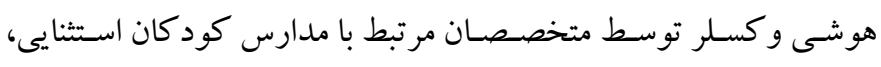

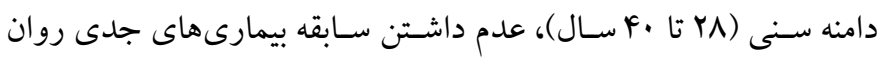

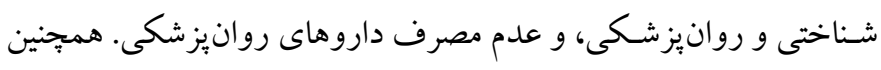

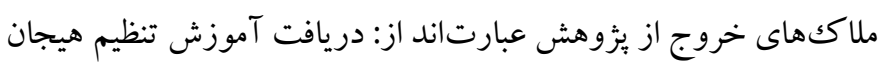

1. Ruminative Responses Scale (RRS)

2. Response Styles Scale (RSS)

3. Nolen-Hoeksema \& Morrow 


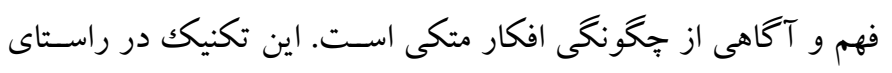

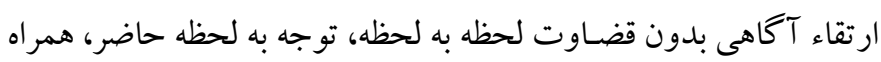

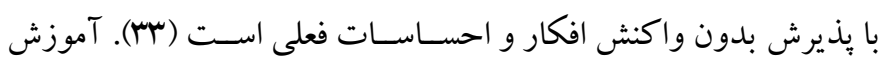
ذهن آكاهى توسط نويسنده نخست اين مقاله در طى 1 جلسه •و و دقيقهاى

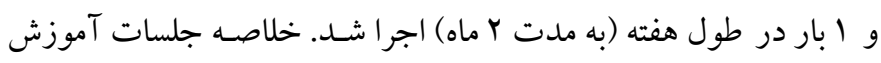
ذهن آكاهى در جدول ب ارائه شده است.

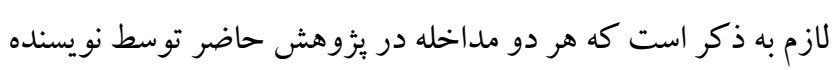

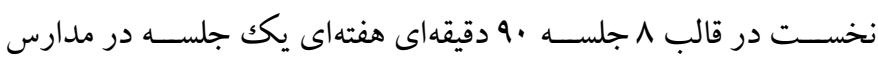
استنائى شهر رشت (استان گيلان) اجرا شد. در هر جلسه ابتدا موارد مورد بحث مشـص مىشد، مهارت هاى جديد به مادران آموزش داده مى شد،

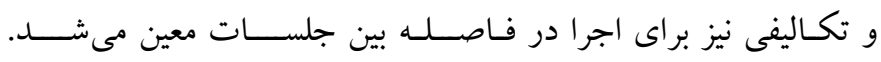

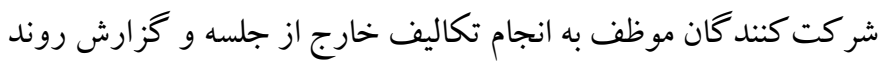

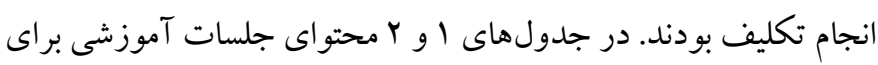
دو گروه آزمايش ارائه شده است.
قبول مقياس باسـخ نشـخوارى بود. در يُزوهش حاضـر نيز جهت سـنش

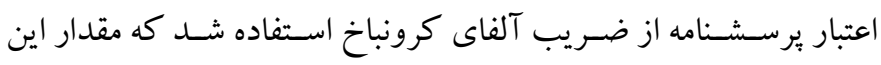

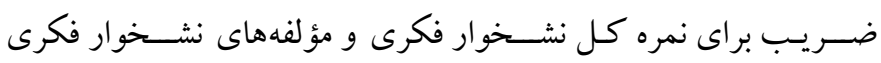

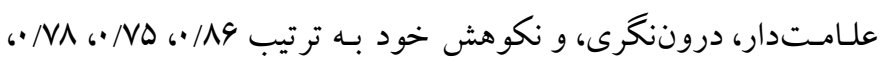
AF/ •به دست آمد. ج) معرفى برنامه مداخلهاى: برنـامه آموزش تنظيم هيجان براسـاس داس

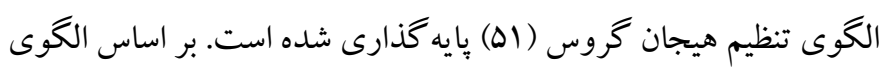
كروس، تنظيم هيجان شـامل همه راهبردهاى آكاهانه و غير آكاهانهاى

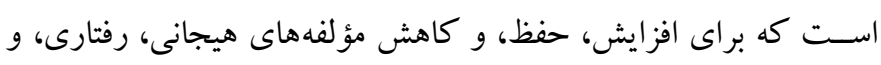

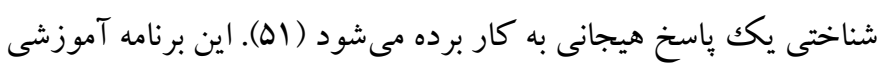
در بززوهش عسخرى و متينى (Dr) مورد استفاده قرار كرفته است.

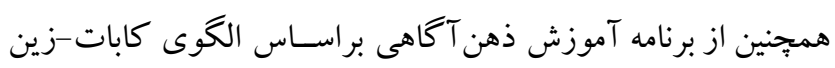

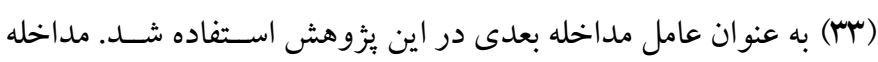

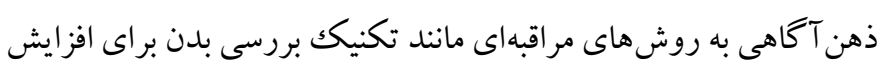

جدول 1: خلاصه جلسات برنامه آموزش تنظيم هيجان (1)

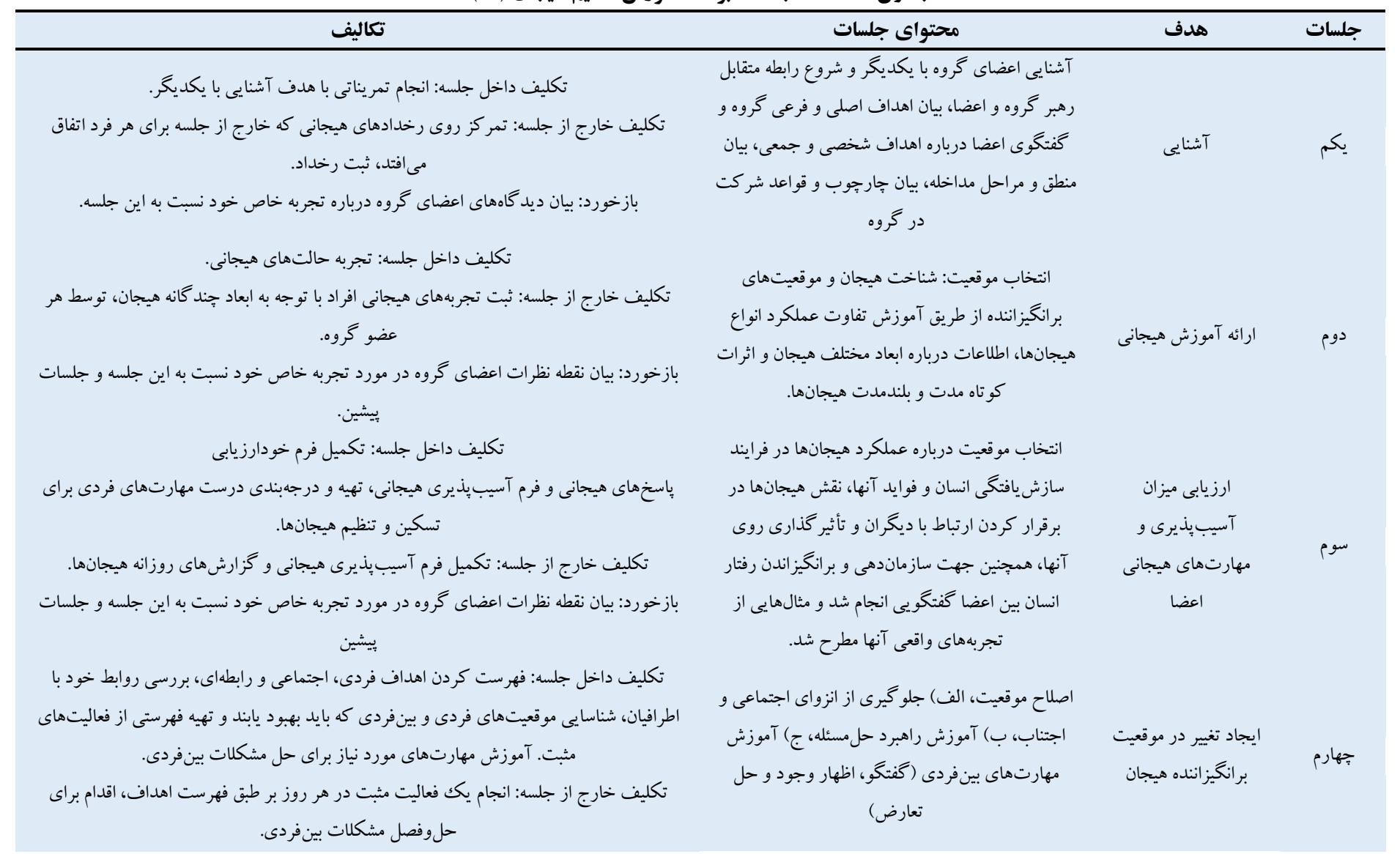


بازخورد: بيان نقطه نظرات اعضاى گروه در مورد تجريه خاص خود نسبت به اين جلسه و جلسات

$$
\text { بيشين. }
$$

تكليف: از اعضا خواسته شد كه در طول هفته هر كاه با حالت هيجانى خاصى مانند غم، خشم و

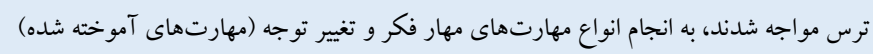

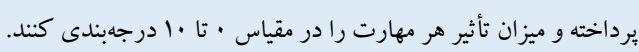

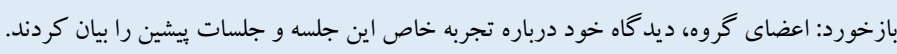

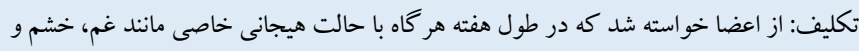

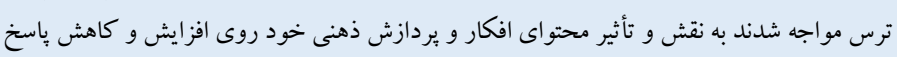

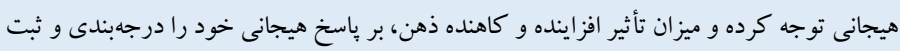

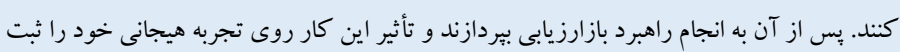
كند.

بازخورد: اعضاى گروه، ديد گاه خود درباره تجربه خاص اين جلسه و جلسات بيشين را بيان كردند.

تكليف: به كار بردن مهارتهاى ابراز هيجان و تعديل ياسخ در هنگام در گيرشدن در تجربههاى هيجانى.

بازخورد: اعضاى گروه، ديد كاه خود درباره تجربه خاص اين جلسه و جلسات ييشين را بيان كردند. تكليف: مراحل اقدام تو سط خود افراد تعيين شد و براى كاربرد برنامه در زندگى واقعى برنامهريزى شد.

بازخورد: يكك ارزيابى كيفى از كل برنامه به صورت كتبى و در ياسخ به اين سؤال كه كل برنامه را

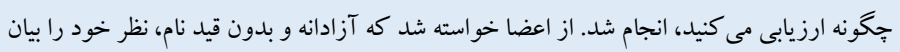

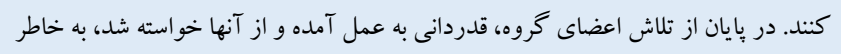
موفقيتهايشان به خودشان باداش دهند.
يُنجم

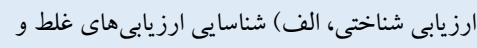

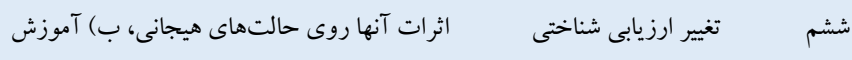
راهبرد بازارزيابى

تعديل ياسخ، () شناسايى ميزان و نحوه استفاده از

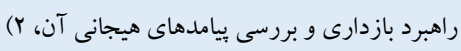

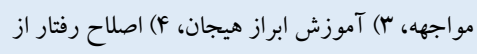

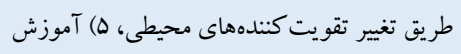

تغيير ييامدهاى رفتارى و فيز يولوزيكى هيجان هفتم تخليه هيجانى، آرميدگى و عمل معكوس.

ارزيابى و كاربرد، دستور جلسه: () ارزيابى ميزان نيل

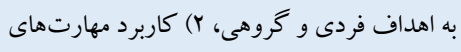

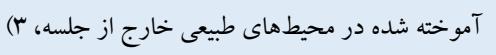
ارزيابى مجدد و رفع موانع كاربرد بر رسى و رفع موانع انجام تكاليف.

جدول r: خلاصه جلسات برنامه آموزش ذهن آكاهى (Tr)

\begin{tabular}{|c|c|c|c|}
\hline تكاليف & محتواى جلسات & هدف & 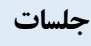 \\
\hline تكليف: انجام يكى از كارهاى روزمره با ذهن آكاهى و & 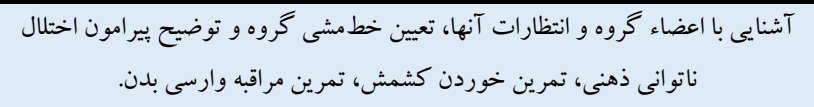 & هدايت خود كار & 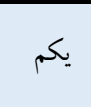 \\
\hline تكليف: آوردن توجه به يكى ديخر از كارهاى روزمره، ثبت & ده دقيقه تنفس با ذهن آكاهى، تمرين وارسى بدن. & جإلش با مانع & دوم \\
\hline تكليف: بيادمروى آكاهانه، وارسى بدن، ثبت تجربههاى & تمرين حر كات كششى همراه با ذهن آكاهى، تمرين قدمزدن آكاهانه، تمرين وارسى & ذهن آكاهى در حين حركت & 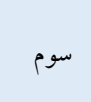 \\
\hline 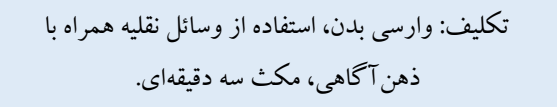 & تمرين ذهن آكاهى نسبت به شنيدن و فكر كردن، داستان ببرهاى گرسنه، تمرين مكث سه & 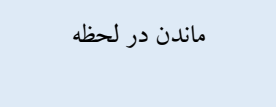 & جهارم \\
\hline تكليف: وارسى بدن و مكث سه دقيقهاى & 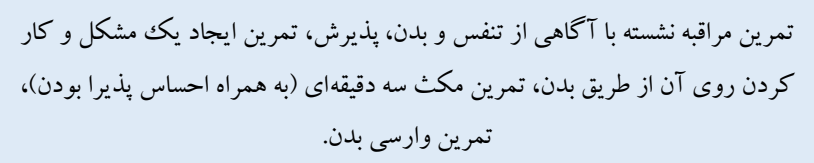 & يذيرش و اجازه دادن & ينجم \\
\hline تكليف: وارسى بدن، مكث سه دقيقهاى و استفاده از آن در & افكار جانشين، تمرين مكث سه دقيقهاى، تمرين وارسى بدن. & افكار واقعيت نيستند & 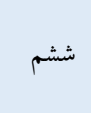 \\
\hline تكليف: تهيه فهرستى از فعاليتهاى انرزىبخش و & ارتباط بين خلق و احساسات، جِگونه به بهترين نحو از خود مراقبت كنيم، تمرين وارسى & 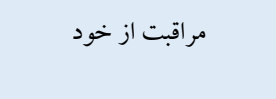 & \\
\hline
\end{tabular}




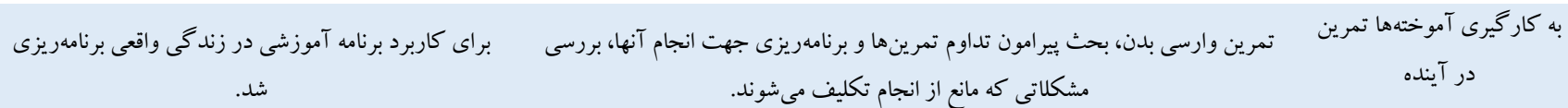

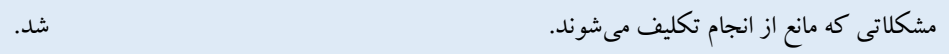

افر اد هر ســه كروه اطمينـان داده شـــد كـه اطلـاعـات آنها محرمانه باقى مى ماند. در يايان بعد از جمع آورى دادهها، تجزيه و تحليل با اســتفاده از تـحـليـل كوواريـانس تـك متغيرى و جنــدمتغيرى در محيط نرم افزار SPSS-22

مافتهان ميـانگين و انحر اف معيار نمرات بيش آزمون- بس آزمون متغير نشــخوار

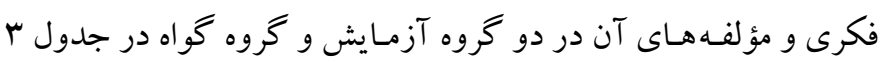
ارائه شده است.
د) روش اجرا: بس از اخـذ مجوزهـاى للـازم جهت انجام بزّوهش، افراد نمونه به شـرحى كه در بخش روش ارائه شــد انتخاب و در ســهـ كروه

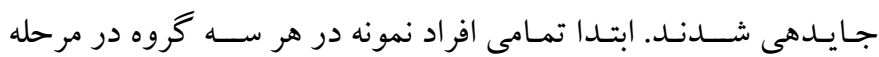
بيش آزمون مورد ارزيابى قرار گرفتند و در مرحله بعد دو گرووه آزمايش، مداخلات للام رادريافت كردند و در نهايت از هر سـه گرووه، يس آزمون به عمل آمد. جهت رعايت اخلاق در يزٔوهش، رضـايت شر كت كنند كان به طور كامل كسـب شد و از اهداف و تمام مر احل مداخله به طور كامل آكاه شــدند. به افراد كروه كواه نيز اطمينان داده شــد كه آنان نيز يس از اتمـام فراينــ يزٔوهش اين مـداخلات را دريافت خو اهند كرد. همجِنين به

جدول "ّ: شاخصهاى توصيفى نشخوار فكرى و مؤلفههاى آن به تفكيك تروههاى ثخوهش

\begin{tabular}{|c|c|c|c|c|c|c|}
\hline كشيدگى & كجى & انحراف معيار & ميانغين & كروه & مرحله & مؤلفه \\
\hline . $/ 9 \Delta r$ & .191. & $r / 919$ & $\Delta r / F I V$ & تنظيم هيجان & & \multirow{6}{*}{ نمره كل نشخوار فكرى } \\
\hline$-1 / Y \Delta 9$ & $\cdot / 4 \wedge 9$ & r/FAG & $\Delta F / / q V$ & ذهن آكاهى & بيش آزمون & \\
\hline$-1 / 1 \cdot 4$ & $-\cdot / r \cdot 1$ & $F / 9 Y 1$ & $\Delta F / F I V$ & كواه & & \\
\hline$\cdot / \wedge 91$ & $\cdot / \Delta \Delta 1$ & D/AYG & Tr/TQ. & تنظيم هيجان & & \\
\hline$-1 / 49$. & $-\cdot / 11 \%$ & $\Delta / 949$ & HF/FIV & ذهن آكاهى & يس آزمون & \\
\hline.$- / 491$ & $\cdot / N r \Lambda$ & $9 / 099$ & $\Delta r / \Delta \ldots$ & كواه & & \\
\hline •/Mrr & $-1 / \cdot 19$ & I/YF. & rM/هAr & تنظيم هيجان & & \multirow{6}{*}{ نشخوار فكرى علامتدار } \\
\hline$-1 / V Y \Lambda$ & $\cdot 11 \cdot 1$ & $1 / 49 V$ & $r 1 / 99 \mathrm{~V}$ & ذهن آكاهى & بيش آزمون & \\
\hline . / FFF & $-\cdot / \Delta r$ & l/949 & Tr/ATr & كواه & & \\
\hline$-\cdot /$ TYA & $\cdot / r V I$ & r/IrA & $1 F / 19 \mathrm{~V}$ & تنظيم هيجان & & \\
\hline$-\cdot / 9 \Delta r$ &.$/ 1.9$ & $r / f V G$ & $|Q / F| V$ & ذهن آكاهى & يس آزمون & \\
\hline l/No & $\cdot / \Delta \Delta \Delta$ & F/VYA & YY/FIV & كواه & & \\
\hline$\cdot 19 \cdot 9$ & - /Arr & $1 / 191$ & $\mid r / \Delta \cdots$ & تنظيم هيجان & & \multirow{6}{*}{ دروننگرى } \\
\hline$-1 / 4 \pi$ &.$/$ IFF & $1 / \Delta F \Delta$ & $I r / N Q$ & ذهن آكاهى & ي بيش آزمون & \\
\hline$-\cdot / \mathrm{V}$ &.$/ .+41$ & $1 / 999$ & سתוז/r & كواه & & \\
\hline$-1 / 194$ &.$- / .19$ & $1 / r \Delta V$ & q/ro. & تنظيم هيجان & & \\
\hline 1/WG & $1 / 4 \Delta 1$ & $1 / \Delta 9 \Delta$ & $\checkmark$ & ذهن آكاهى & 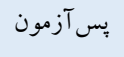 & \\
\hline $1 / 991$ & $-1 / \Delta 9 \Delta$ & Y/QGF & $1 Y / 99 \mathrm{~V}$ & كواه & & \\
\hline.$- / 94 \Delta$ & - /Arg & $r / 4 q \Lambda$ & 19/TrT & تنظيم هيجان & & \multirow{6}{*}{ كوهش خود } \\
\hline.$- / 90 r$ &.$/ 149$ & $1 / 914$ & M/VQ. & ذهن آكاهى & بيش آزمون & \\
\hline rוr/•- & $-\cdot 191$ & $r / \cdot Q F$ & IN/TQ. & كواه & & \\
\hline$-1 / 49$. & ./YVq & r/YIF & Ir/ATr & تنظيم هيجان & & \\
\hline$-\cdot / Y Y F$ & . MIT & r/DQF & ir & ذهن آكاهى & پِ آزمون & \\
\hline . /9r. & $1 / r \cdot r$ & $F / r \cdot q$ & $|N / F| V$ & كواه & & \\
\hline
\end{tabular}


از آزمون لوين استفاده شد. نتايج نشان از عدم معنادارى آزمون لوين در

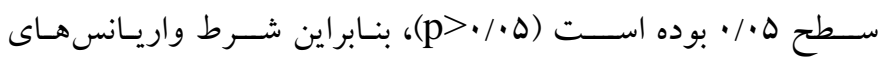

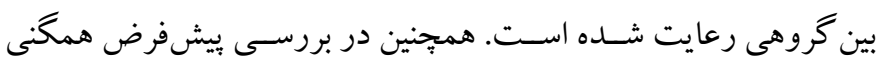

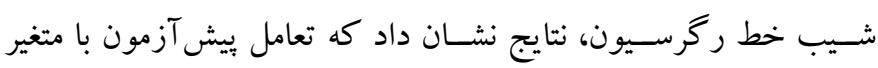

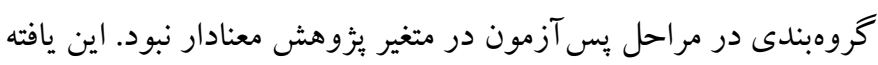

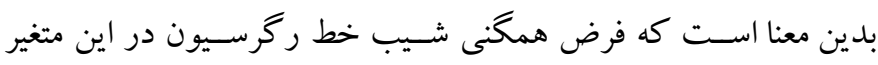

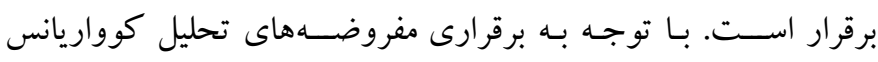

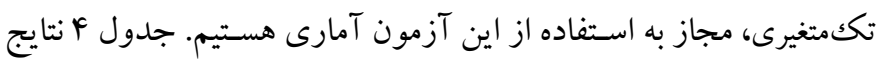
تحليل كوواريانس تككمتغيرى را براى بررسى تفاوت گروههاى آزمايش إنس و گگ اه در نشخوار فكرى كلى نشان داده است.
مطابق جدول سا، ميانگين نمرات نشـخوار فكرى و مؤلفههاى آن در

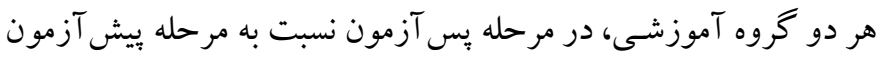

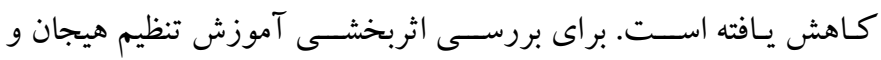

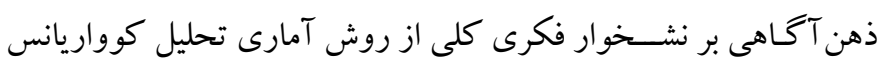

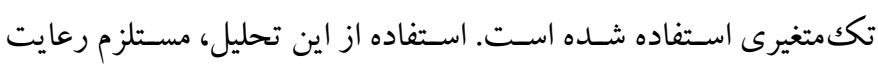
بيشفرض هايى است كه بيش از اجراى آزمون مورد بررسى قرار كرفتند.

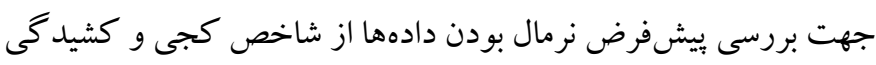

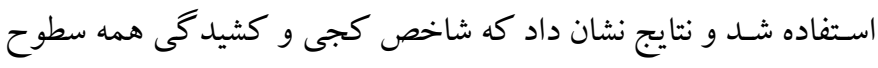

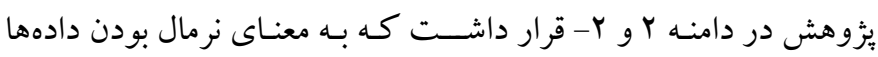

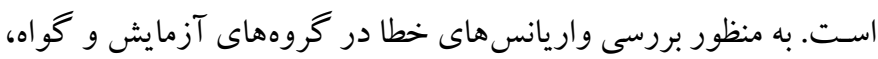

جدول ع: نتايج آزمون تحليل كواريانس تكمتغنيرى براى تيين تفاوت يين كروهى در نشخوار فكرى كلى

\begin{tabular}{|c|c|c|c|c|c|c|c|}
\hline توان آزمون & مجذور اتا & $\mathbf{p}$ & $\mathbf{F}$ & MS & Df & SS & منبع \\
\hline 1 & $\cdot / 210$ & $\cdot / \cdots$ & rG/VDF & 1. HN/YF. & $r$ & MIIF/VYI & الكوى تصحيح شده \\
\hline$\cdot / \cdot \wedge \Delta$ &.$/ 1$ & $\cdot / \Delta \mathrm{VV}$ & הוT/. & Ir/MrY & 1 & IT/MTY & يِيش آزمون \\
\hline \multirow[t]{2}{*}{1} & $\cdot / N 11$ & $\cdot / \cdots$ & $r q / \mu r$. & $1 \Delta r \Delta / q \cdot F$ & r & $\mu \cdot \Delta 1 / \Lambda \cdot \Lambda$ & كروه \\
\hline & & & & $r \Lambda / \Lambda \cdot V$ & rr & IYFI/AKF & خطا \\
\hline
\end{tabular}

مى توان كفـت كـه آموزش تنظيم هيجـان و ذهن آكَاهى موجب كاهش

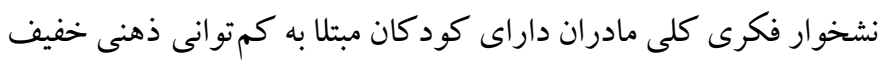

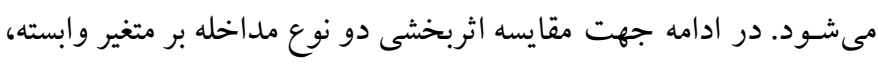

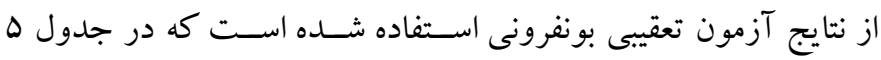

كزارش شده است.

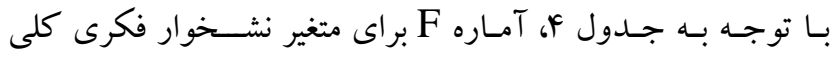

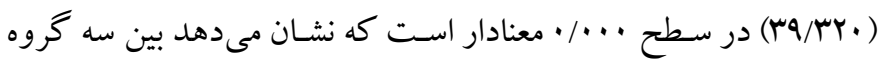
در ميز ان نشخوار فكرى كلى تفاوت معنادارى وجود دارد. همجنين ميزان

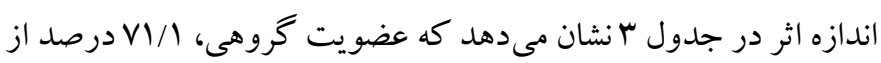

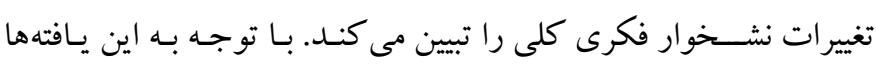

جدول 0: نتايج مقايسه زوجى متغير وابسته در كروههاى آزمايش

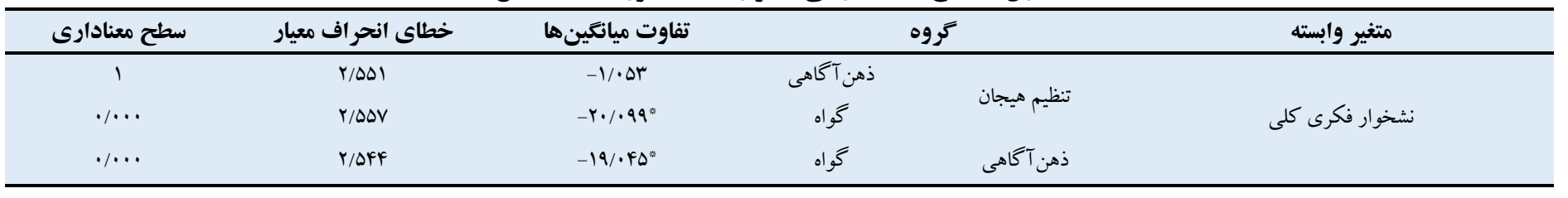

فكرى كلى آزمودنىها منجر شـده و تأثير دو روش آموزش بر نشـخوار

$$
\text { فكرى كلى يكسان بوده است. }
$$

در ادامه براى بررسى اثربخشى آموزش تنظيم هيتجان و ذهن آكاهى بر هر يكك از خردهمقياسهاى نشـخوار فكرى افراد نمونه از روش آمارى تحليل كوواريانس جندمتغيرى استفاده شد. استفاده از اين تحليل، مستلزم
نتايج آزمون بونفرونى در جدول ه نشان مىدهد كه در متغير نشخوار فكرى كلى، تفاوت بين دو گروه آزمايش با گروه گو اه معنادار اســت

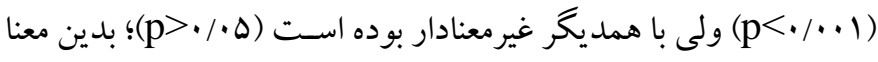
كه هر دو روش آموزشسى در مقايسـه با كروه گو اه، به كاهش نشـخوار 


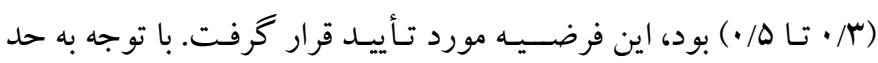

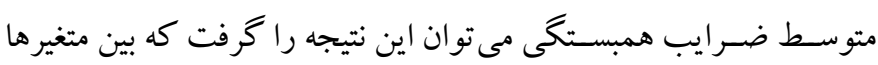

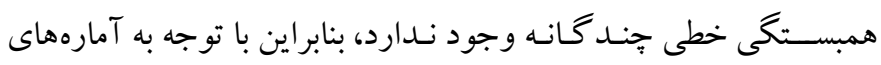
جندمتغيرى مربوطه يعنى معنادار نبودن لامبداى ويلكز در ســــ هُ اطمينان

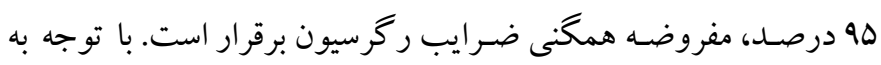
برقرارى مفروضسههاى تحليل كوواريانس جندمتغيرى، مجاز به استفاده از

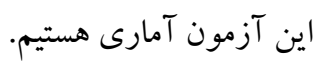
براى تعيين اثر كلى متغير گرووه بر مؤلفههاى نشخوار فكرى از آزمون

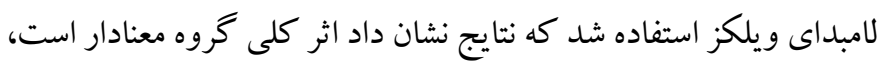
زيرا F مربوط بـه هر جهار آزمون اثر ييلـيى (N/IAF)، لـامـداى ويلكز

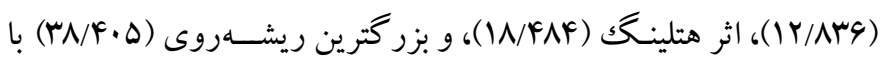

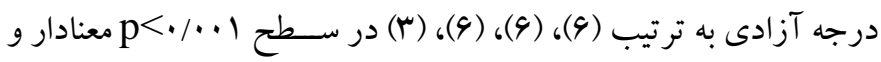

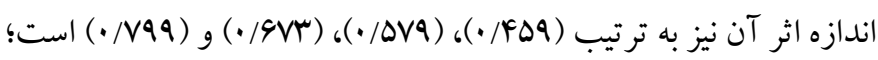
يعنى بين گروههاى آزمايش و گو اه حداقل در يكى از مؤلفههاى نشخوار

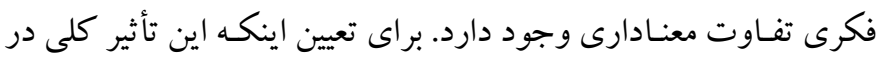
كـدام يـك از مؤلفـهــاى نشــخوار فكرى وجود دارد، نتـايج تحليـل كوواريانس در جدول 9 ارائه شده است.
رعايت يِشفرضهايى است كه يیش از اجراى آزمون مورد بررسى قرار

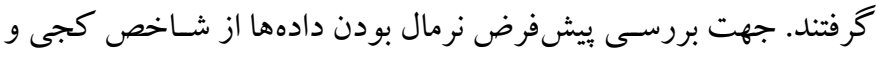

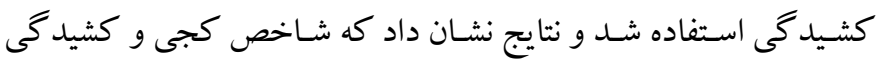
همه ســـوح يثزوهش در دامنه Y و Y- قرار داشــت و اين به معناى نرمال بودن دادهها اسـت. به منظور بررسى واريانس هاى متغيرهاى بثزوهش در

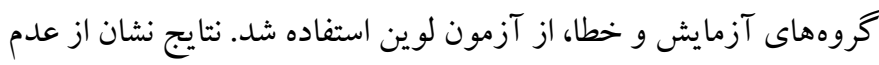

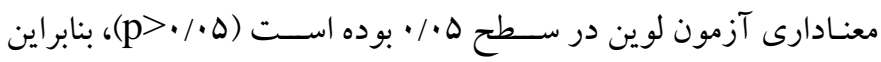

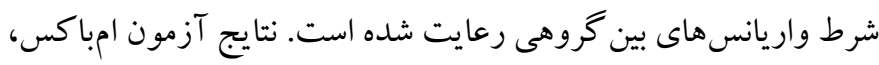
همخن بودن ماتريس كوواريانس متغيرهاى وابسته در تمامى سطوح متغير

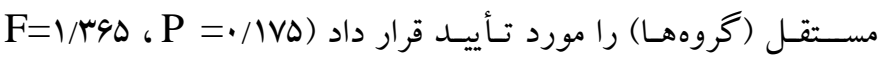

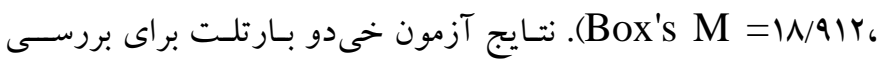

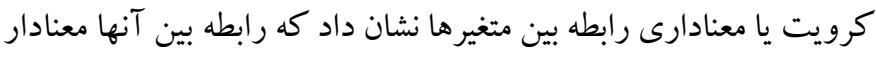

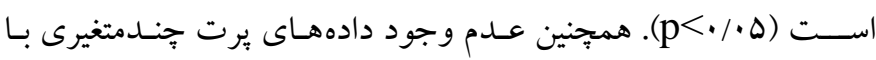

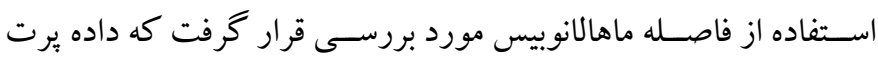

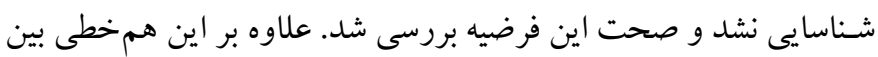

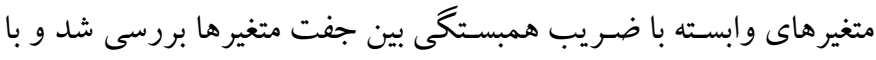

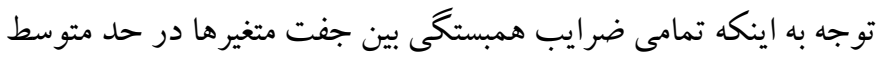

جدول 7: نتايج آزمون تحليل كواريانس جندمتغيرى براى تبيين تفاوت بين كروهى در مؤلفههاى نشخوار فكرى

\begin{tabular}{|c|c|c|c|c|c|c|c|c|}
\hline توان آزمون & مجذور اتا & $\mathbf{P}$ & $\mathbf{F}$ & MS & df & SS & \multicolumn{2}{|c|}{ مؤلفه هاى نشخوارفكرى } \\
\hline.$/ 914$ &.$/ \Delta 1 Y$ & $\cdot / \cdots$ & $9 / Y M$ & $9 \Lambda / F \Delta V$ & $\Delta$ & FQY/YAF & نشخوار فكرى علامتدار & \\
\hline 1 & $\cdot / v \cdot 9$ & $\cdot / \cdots$ & $1 F / 94 A$ & Gr/FVr & $\Delta$ & MIT/Mar & دروننگرى & الكوى تصحيح شده \\
\hline.$/ 994$ & $\cdot / 4 \Delta Q$ & $\% / \cdot r$ & $\Delta / \cdot q \mu$ & $91 / 901$ & $\Delta$ & $r \cdot q / v \wedge q$ & نكو هش خود & \\
\hline$\cdot / 9 \vee \wedge$ & $\cdot / 4 \cdot V$ & $\cdot \cdots$ & $1 \cdot / \mu \cdot 1$ & $191 /$ rar & r & TrYMAY & نشخوار فكرى علامتدار & \\
\hline 1 & .1909 & $\cdot / \cdots$ & TN/GKT & $\mid Y r / I \Delta V$ & r & YKF/MIF & دروننخرى & خروه \\
\hline.$/ 9 V V$ & $\cdot / 4 \cdot f$ & $\cdot / \cdots$ & $1 . / 1 V 9$ & IrT/Var & r & MAF/Q91 & نكو هش خود & \\
\hline
\end{tabular}

تغييرات نكوهش خود را تبيين مى كنـد. بـا توجـهـ بـهـ اين يـافتها مـى توان

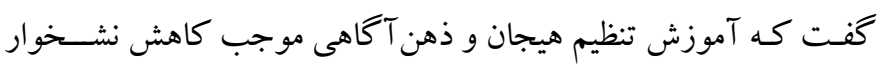

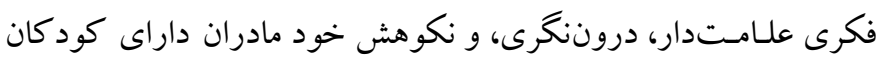

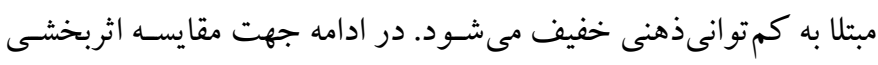

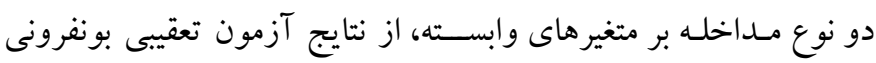
استفاده شده است كه در جدول Vز عزارش شده است.
بـا توجسه بـه جـدول، 9 آمـاره F براى مؤلفـهــاى نشـخوار فكرى

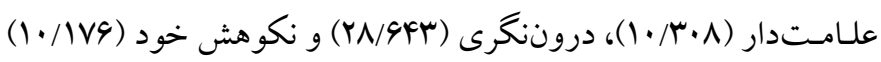

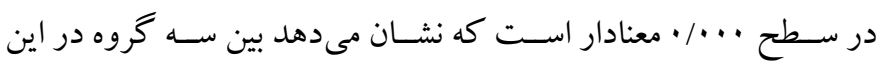
مؤلفهها تفاوت معنادارى وجود دارد. همجنين ميزان اندازه اثر در جدول

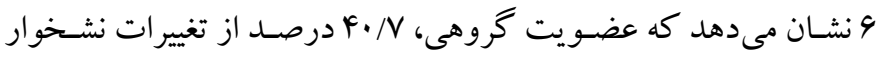

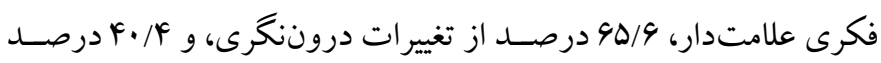


جدول Ү: نتايج مقايسه زوجى مؤلفههاى نشخوار فكرى در كروههاى آزمايش

\begin{tabular}{|c|c|c|c|c|c|}
\hline سطح معنادارى & خطاى انحراف معيار & تفاوت ميانكينها & & & متغير وابسته \\
\hline 1 & $1 / V \Delta 1$ & $-1 / 91 \mathrm{~V}$ & ذهن آكَاهى & & \multirow{3}{*}{ نشخوار فكرى علامتدار } \\
\hline.$/ .1$ & I/AMs & $-\Lambda / \cdot \Delta^{*}$ & كواه & يججار & \\
\hline$\% r$ & I/VDF & $-9 / \Gamma \wedge V^{*}$ & كواه & ذهن آكاهى & \\
\hline 1 & $. / 9 / f$ & $-\cdot / Y V \Delta$ & ذهن آكاهى & & \multirow{3}{*}{ دروننخرى } \\
\hline$\cdot / \cdots$ & $\cdot / 9 \wedge \mathrm{F}$ & $-9 / 4 \pi V^{*}$ & كو كواه & & \\
\hline$\cdot / \cdots$ &.$/ 919$ & $-9 / 19 Y^{\circ}$ & كواه & ذهن آكاهى & \\
\hline 1 & l/DFT & $1 / \wedge r$ & ذهن آكاهى & & \multirow{3}{*}{ نكوهش خود } \\
\hline.$/ \cdots 4$ & $1 / 991$ & $-\Delta / 9 \pi \mu^{*}$ & كواه & E & \\
\hline$\cdot \cdots$ & $1 / D F G$ & $-9 / \mathrm{V} \cdot 4^{\prime \prime}$ & كواه & ذهن آكاهى & \\
\hline
\end{tabular}

كاهش نشـخوار فكرى مؤثر اسـت. همجنين مر ادى كيا و همكاران (YV)

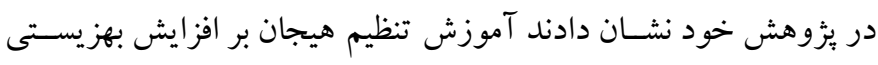

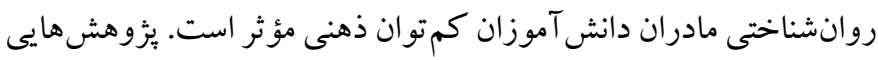

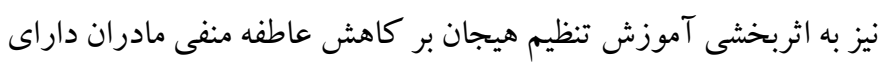

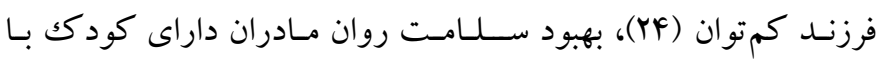
فزون كنشسى / نارسـايى توجه (YD)، و افزايش سـلامت روان مادران داراى

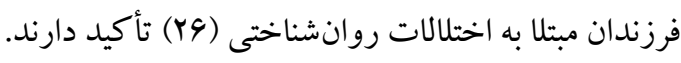
در تبيين اين يـافته مى توان گفـت از آنجايى كـه هيجان دربردارنده راهبردهاى منفى (سـازشنايافته) و مثبت (سازش يافته) است، در ارتباط با ديا

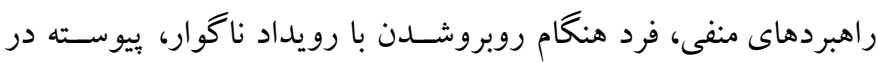

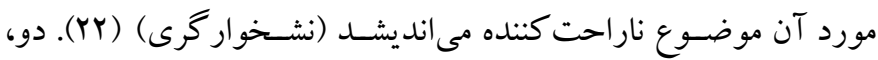

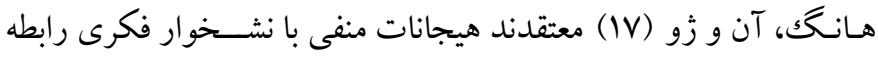
دارنـد؛ بنـابر اين ارزيـابى هيجـانـات بيش از ايجاد آنها، افزون بر اينكه از

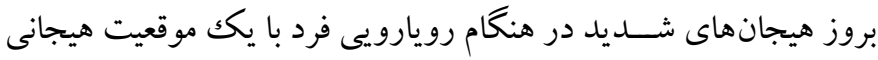

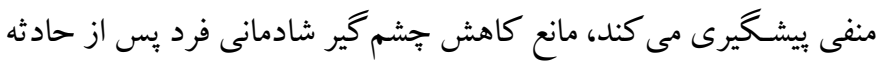

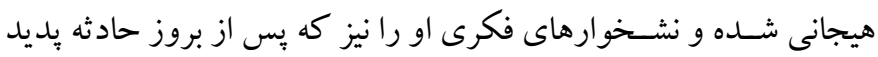

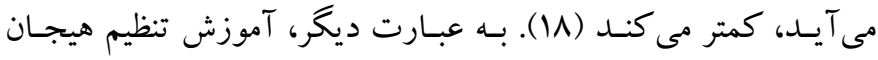

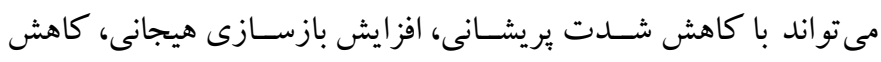

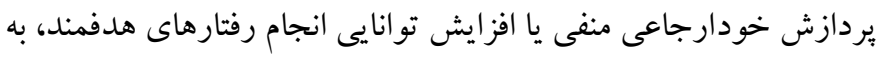

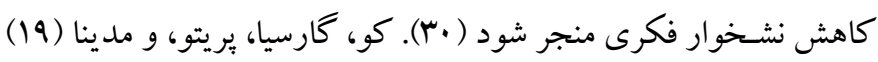
معتقـنــــ آموزش تنظيم هيجـان از طريق بـهـكار گيرى راهبردهايى مانند
نتايج آزمون بونفرونى در جدول V نشـان مىدهد كه در مؤلفههاى

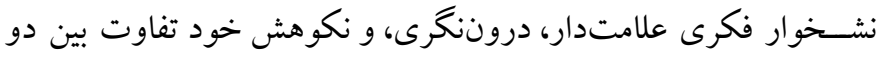

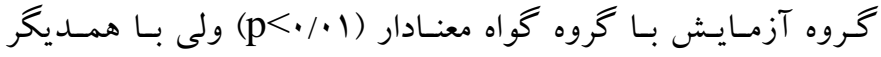

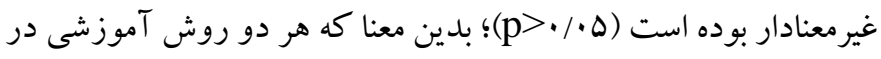

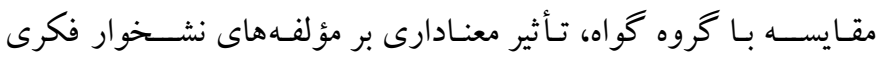

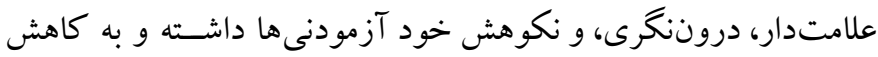
اين مؤلفها در آزمودنىها منجر شـده است و تأثير دو روش آموزشى بر مؤلفههاى نشخوار فكرى نيز يكسان بوده است.

\section{بحث و نتيجه كيرى}

در يزوهش حاضـر، به مقايسه و تعيين اثربخشى آموزش تنظيم هيجان و

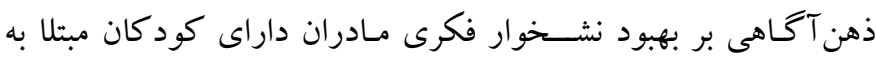
كم توانى ذهنى خفيف يرداخته شد. نتايج تحليل دادها نشان داد ماد كه تأثير

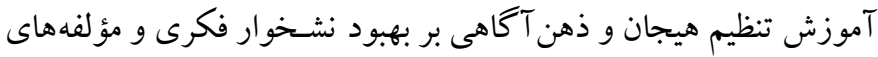

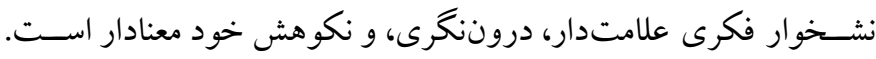
همجنين نتايج حاصل از آزمون مقايسه ميانگين ها نشان داد كه بين تأثير

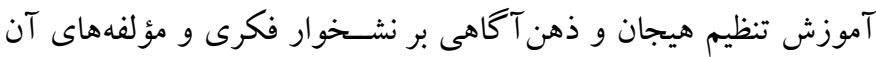
تفاوت معنادار وجود نداشت.

يـافته بـه دســت آمـده مبنى بر تأثير آموزش تنظيم هيجان بر بهبود

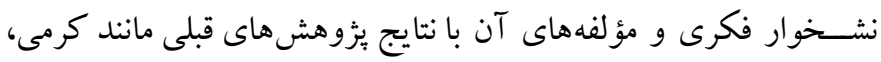

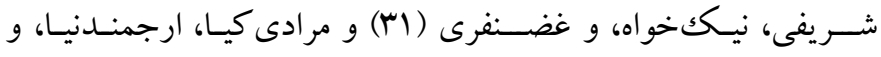

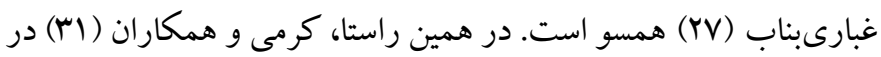

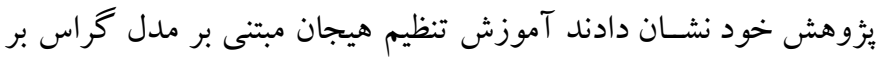


رفتارى نامناسـبـ مىشــود كه ســلامت روان مادران را تحت تأثير قرار

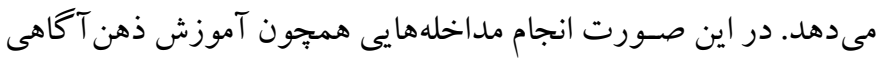

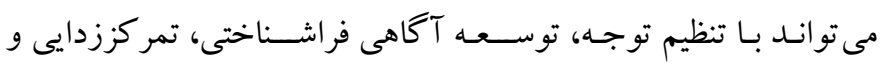

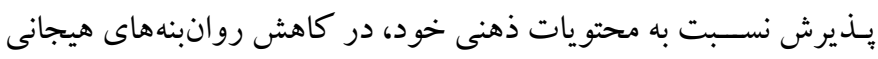

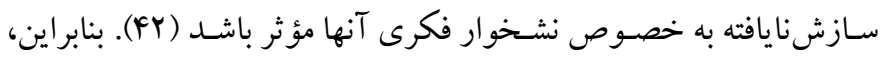

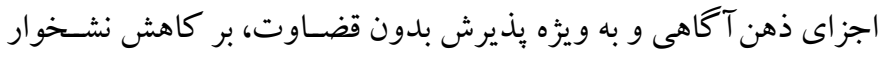

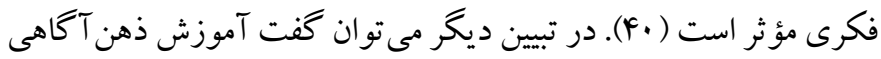

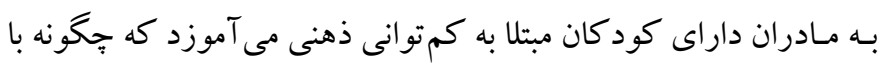

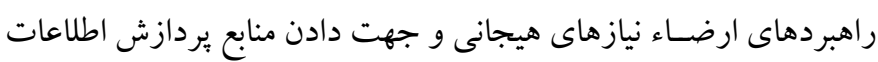
به اهداف خنثى توجه كرده و مانند تنفس و حس لحظه، شـرايط را براى

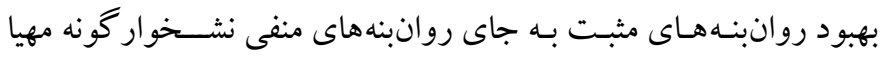

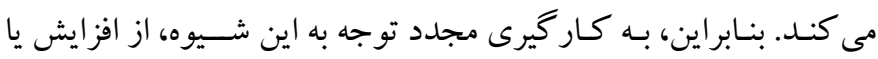

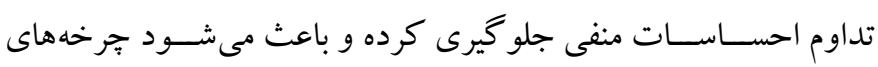

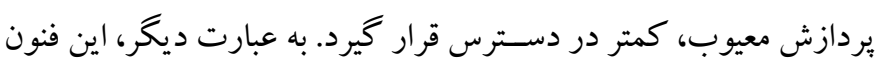

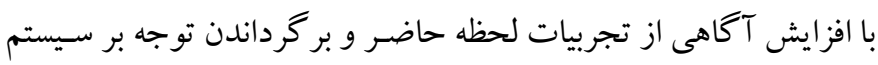

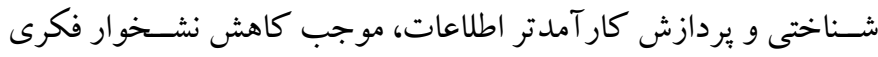
مىشود (س) (1). در تبيين عـدم تفـاوت بين آموزش تنظيم هيجـان و ذهن آكَاهى،

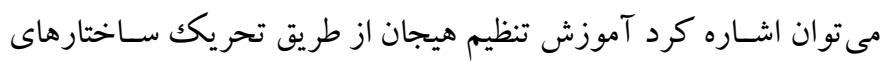

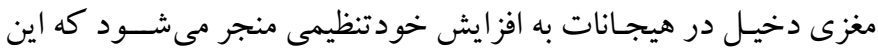

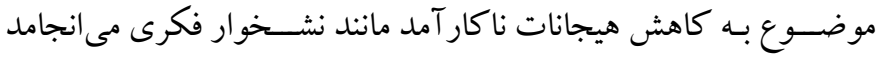

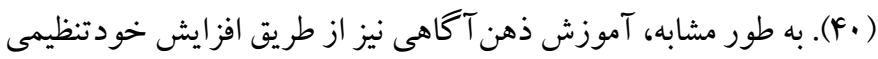

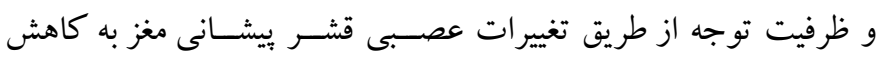

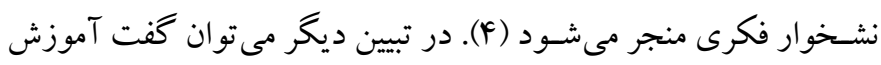

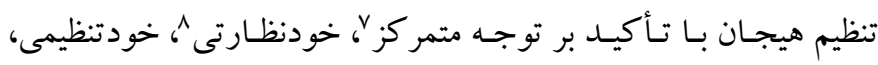

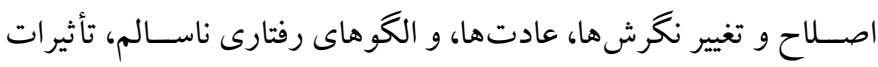

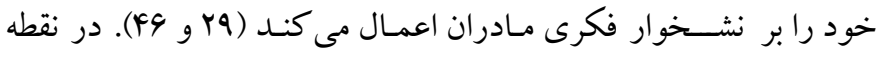

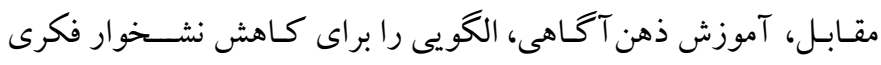

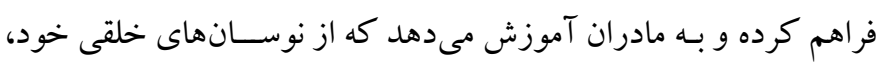

5. Focused attention

6. Self-monitoring

7. Focused attention

8. Self-monitoring

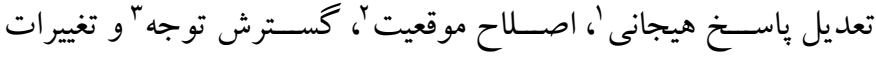

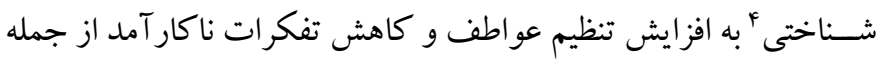

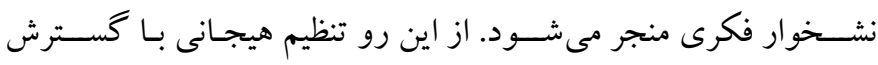

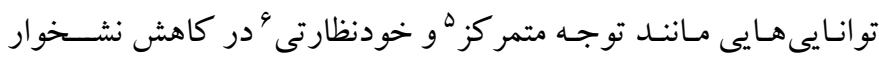
فكرى مادران داراى فرزند مبتلا به كم توانى ذهنى مؤثر است. همجينين يافتهاى به دست آمده در اين مطالعه مبنى بر تأثير آموزش

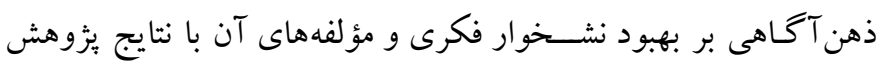

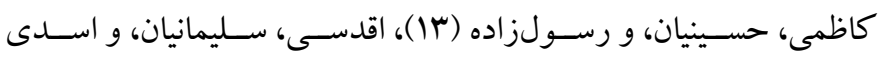

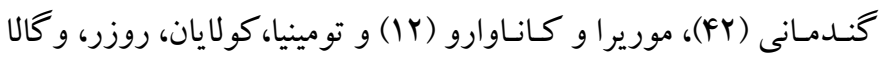

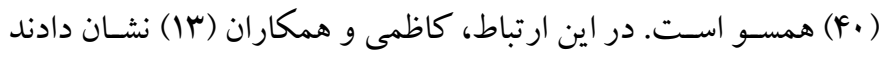

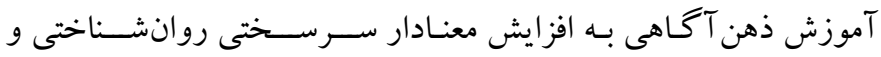

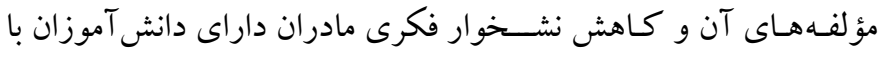

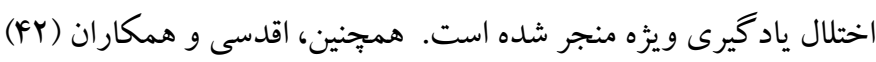

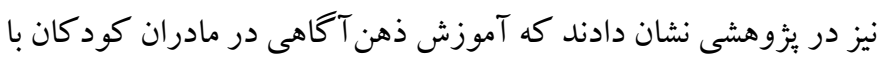

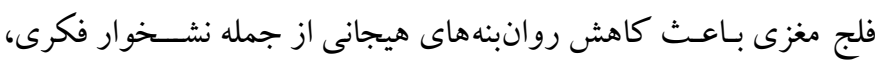

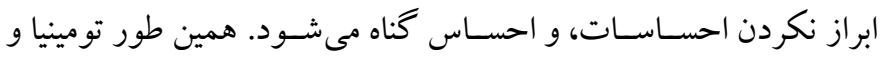

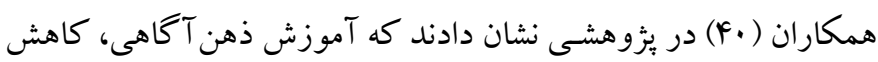

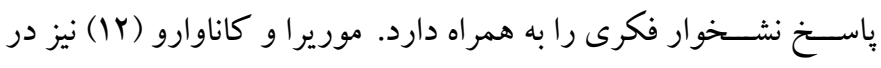

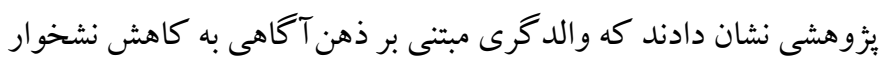
فكرى و تنيدگى والدين منجر مى شود.

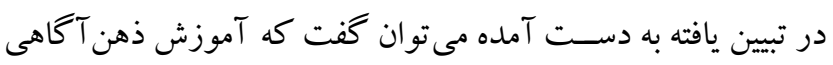
تلاش مى كند از طريق فنونى مانند توجه به تنفس و بدن و و معطوف كرد دهن

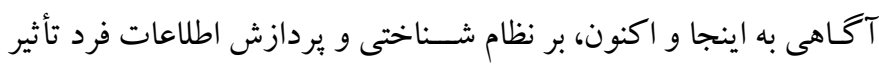

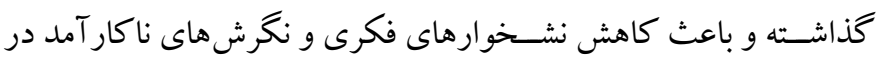
افراد مىشــود (F4). در تبيين ديخر مى توان كفــت از آنجايى كه مادران

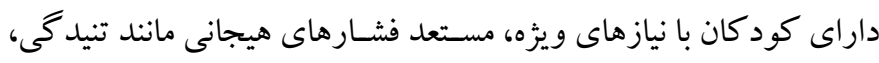

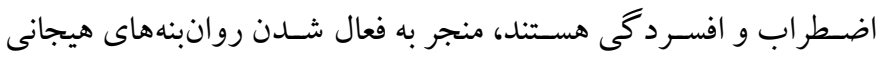

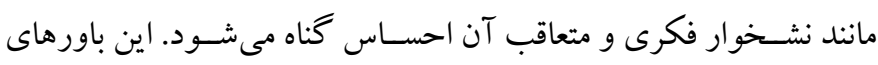

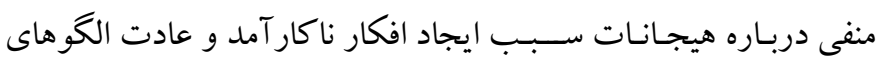

1. Emotional response

2. Situation modification

3. Attentional deployment

4. Cognitive change 
كاهش مشككلات روانشـناختى به خصوص نشخو ار فكرى مورد استفاده

قرار كيرد.

ملاحظات اخلاقى

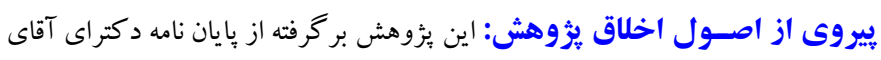

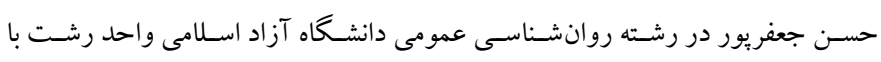

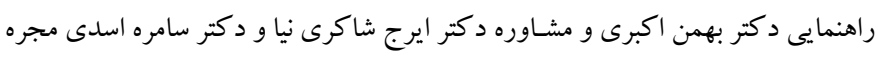

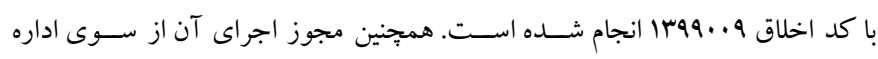

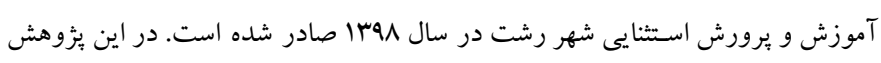

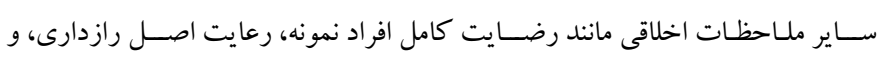
محرمانه ماندن اطلاعات نيز در نظر كرفنه شده است.

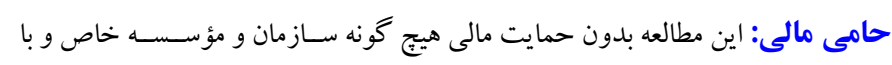

$$
\text { هزينه شخصى نويسنده نخست انجام شده است. }
$$

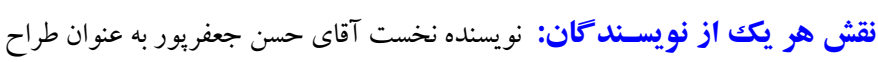

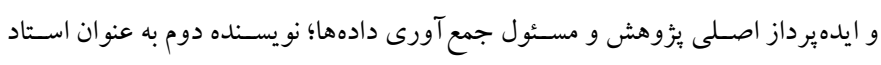

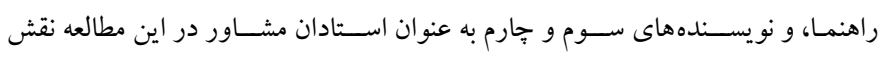

داشتهاند. تضـاد منافع: بر اسـاس اعلام نويســد كان، در اين مقاله تضاد منافع براى هيج كدام از

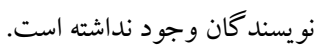

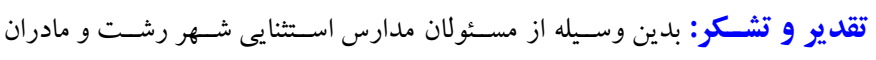
دانش آموزان اين مدارس كه در اين يُروهش شر كت داشتند، تشكر و قدردانى مى شود.
آكـاهى داشــــه بـاشـــد و از فنون ذهن آكاهى براى آكاهى از بردازش اطلاعاتى كه افكار و هيجانات را تداوم مىبخشند، به خوبى استفاده كنند.

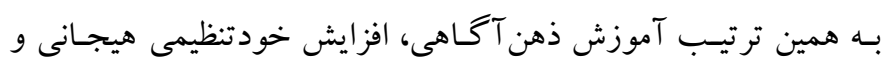

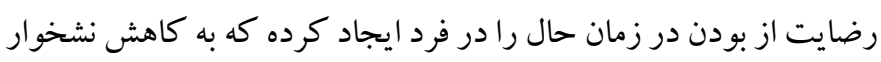

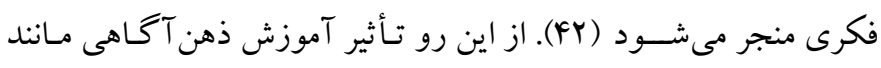

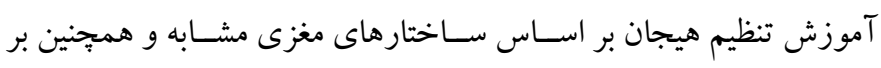

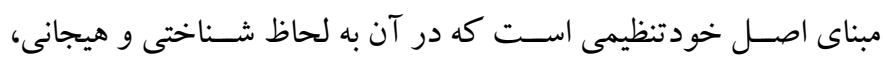

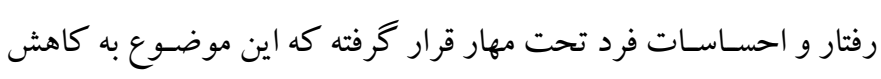

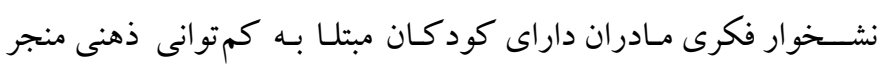

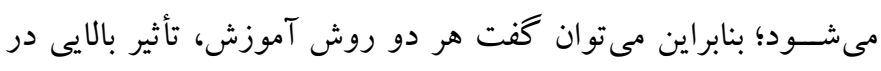

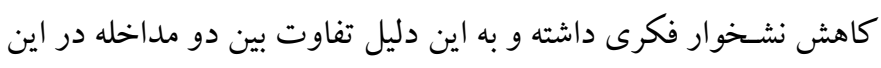

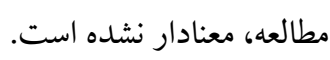

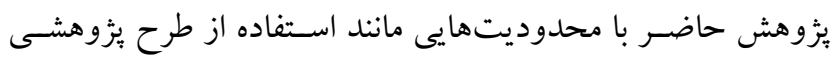

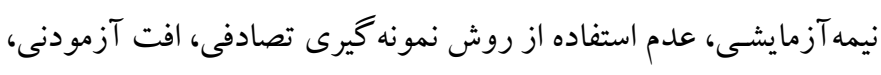

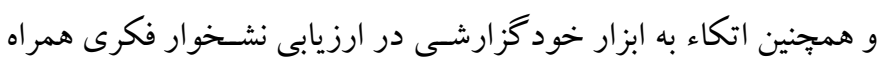

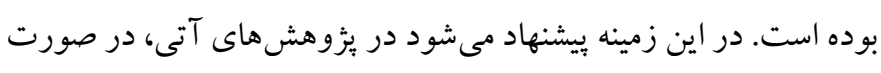
امكان از روش كاملاً آزمايشسى با تعداد حجم نمونه بيشـتر استفاده شـود.

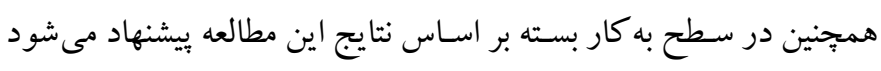

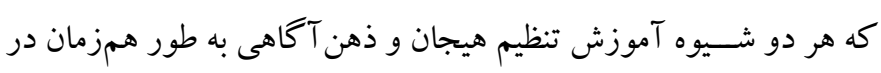




\section{References}

1. Bethell CD, Read D, Stein REK, Blumberg SJ, Wells $\mathrm{N}$, Newacheck PW. Identifying children with special health care needs: Development and evaluation of a short screening instrument. Ambul Pediatr. 2002; 2(1): 38-48. Doi: 10.1367/1539-4409(2002) 002<0 038: icwshc> 2.0.co; 2 [Link]

2. American Psychiatric Association. Diagnostic and statistical manual of mental disorders (DSM-5). Washington, DC, USA: American Psychiatric Pub; 2013. [Link]

3. Jones L, Gold E, Totsika V, Hastings RP, Jones M, Griffiths A, et al. A mindfulness parent well-being course: Evaluation of outcomes for parents of children with autism and related disabilities recruited through special schools. Eur J Spec Needs Educ. 2018; 33(1): 16-30. [Link]

4. Osborn R, Roberts L, Kneebone I. Barriers to accessing mental health treatment for parents of children with intellectual disabilities: A preliminary study. Disabil Rehabil. 2020; 42(16): 2311-2317. Doi: 10.1080/09 638288.2018.1558460 [Link]

5. Flynn S, Hastings RP, Burke C, Howes S, Lunsky Y, Weiss JA, et al. Online mindfulness stress intervention for family carers of children and adults with intellectual disabilities: Feasibility randomized controlled trial. Mindfulness. 2020; 11(9): 21612175. [Link]

6. Lo HHM, Chan SKC, Szeto MP, Chan CYH, Choi CW. A feasibility study of a brief mindfulness-based program for parents of preschool children with developmental disabilities. Mindfulness. 2017; 8(6): 1665-1673. [Link]

7. Moradikia H, Sattarpour Iranaghi F, Emamgholian S. Compare The effectiveness of emotion regulation and resilience training on psychological well-being of mothers of students with intellectual disability. Iranian Journal of Health Education and Health Promotion. 2017; 5(3): 213-223. [Persian]. Doi: 10.30699/ac ad pub.ijhehp.5.3.213 [Link]

8. Gogoi RR, Kumar R, Deuri SP. Anxiety, depression, and quality of life in mothers of children with intellectual disability. Open Jour of Psych \& Allied Scie. 2017; 8(1): 71-75. Doi: 10.5958/2394-2061. 2016.00046.X [Link]

9. Azeem MW, Dogar IA, Shah S, Cheema MA, Asmat A, Akbar M, et al. Anxiety and depression among parents of children with intellectual disability in Pakistan. J Can Acad Child Adolesc Psychiatry. 2013; 22(4): 290-295. [Link]
10. Lee J. Maternal stress, well-being, and impaired sleep in mothers of children with developmental disabilities: A literature review. Res Dev Disabil. 2013; 34(11): 4255-4273. Doi: 10.1016/j.ridd.2013.09.008 [Link]

11. Rodriguez G, Hartley SL, Bolt D. Transactional relations between parenting stress and child autism symptoms and behavior problems. J Autism Dev Disord. 2019; 49(5): 1887-1898. Doi: 10.1007/s 108 03-018-3845-x [Link]

12. Moreira H, Canavarro MC. The association between self-critical rumination and parenting stress: The mediating role of mindful parenting. J Child Fam Stud. 2018; 27(7): 2265-2275. [Link]

13. Kazemi N, Hosseinian S, Rasolzadeh V. Effectiveness of mindfulness education on psychological hardiness and mental rumination in mothers of students with Learning Disabilities. Empowering Exceptional Children. 2019; 10(3): 7184. [Persian]. Doi: 10.22034/ceciranj. 2020. 182834. 1189 [Link]

14. Nolen-Hoeksema S, Wisco BE, Lyubomirsky S. Rethinking rumination. Perspect Psychol Sci. 2008; 3(5): 400-424. [Link]

15. Lewis EJ, Yoon KL, Joormann J. Emotion regulation and biological stress responding: Associations with worry, rumination, and reappraisal. Cogn Emot. 2018; 32(7): 1487-1498. Doi: 10.1080/02699931. 2017. 1310088 [Link]

16. Watkins ER. Rumination-focused cognitivebehavioral therapy for depression. Guilford Publications; 2018. [Link]

17. Du J, Huang J, An Y, Xu W. The relationship between stress and negative emotion: The mediating role of rumination. Clin Res Trials. 2018; 4(1): 1-5. Doi: 10. 15761/CRT.1000208 [Link]

18. Manigault AW, Zoccola PM. Rumination. In: Sweeny K, Robbins ML, Cohen LM, editor. The wiley encyclopedia of health psychology. John Wiley \& Sons, Ltd; 2020, pp: 557-567. [Link]

19. Coo S, García MI, Prieto F, Medina F. The role of interpersonal emotional regulation on maternal mental health. J Reprod Infant Psychol. 2020; 1-19. Doi: 10.1080/02646838.2020.1825657 [Link]

20. McRae K, Gross JJ. Emotion regulation. Emotion. 2020; 20(1): 1-9. Doi: 10.1037/emo0000703 [Link]

21. Gross JJ, John OP. Individual differences in two emotion regulation processes: Implications for affect, relationships, and well-being. J Pers Soc Psychol. 2003; 85(2): 348-362. Doi: 10.1037/0022-3514. 85. 2.348 [Link] 
22. Garnefski N, Koopman H, Kraaij V, ten Cate R. Brief report: Cognitive emotion regulation strategies and psychological adjustment in adolescents with a chronic disease. J Adolesc. 2009; 32(2): 449-454. Doi: 10.1016/j.adolescence.2008.01.003 [Link]

23. Matin H, Akhavan Gholami M, Ahmadi A. The effectiveness of emotion regulation teaching on the parent_child interaction and those mothers that have learning disabilities children. Journal of Learning Disabilities. 2018; 8(1): 70-89. [Persian]. Doi: 10.22098/jld.2018.709 [Link]

24. Javadian SR, Khaleghi L, Fathi M. The effectiveness of emotional regulation training on negative affect and resilience of mothers with disabled children. Iranian Journal of Psychiatric Nursing. 2018; 6(5): 25-33. [Persian]. [Link]

25. Kamali A, Vaghee S, Asgharipour N, Behnam vashani HR. The impact of emotion regulation training on mental health in mothers of children with attention deficit/hyperactivity disorder. Journal of Torbat Heydariyeh University of Medical Sciences. 2016; 4(3): 16-23. [Persian]. [Link]

26. Abyar Z, Rahimi E, Ahmadi Nasrabad Sofla S, Maredpour A, Zamani N. Effectiveness of emotion regulation training on mental health of mothers by children with mental disorders. Health Research Journal. 2017; 2(1): 17-23. [Persian]. Doi: 10.18869/ acadpub.hrjbaq.2.1.17 [Link]

27. Moradikia H, Arjmandnia AA, Ghobari Bonab B. Effectiveness of emotion regulation training on psychological well-being of Mothers of students with intellectual disability. Journal of Pediatric Nursing. 2016; 3(1): 51-60. [Persian]. Doi: 10.21859/jpen0301195 [Link]

28. Arabi Z, Moghaddam LF, Sahebalzamani M. The effect of emotion regulation training on family relationships of hyperactive children. J Educ Health Promot. 2020; 9: 101. Doi: 10.4103/jehp.jehp_738_19 [Link]

29. Wolford SN. Emotion regulation process in parents: Responding to the call for emotion regulation skills in parenting interventions [PhD thesis]. [Florida, United States]: Department of Family and Child Sciences, Florida State University Libraries; 2019, pp: 1-158. [Link]

30. Roemer L, Williston SK, Rollins LG. Mindfulness and emotion regulation. Curr Opin Psychol. 2015; 3: 52-57. [Link]

31. Karami R, Sharifi T, Nikkhah M, Ghazanfari A. Effectiveness of emotion regulation training based on grass model on reducing rumination and social anxiety in female students with 60-day follow-up. Iranian Journal of Health Education and Health Promotion. 2019; 7(1): 1-9. [Persian]. Doi: 10.30699/ijhehp.7.1.1 [Link]

32. Griffith GM, Hastings RP, Williams J, Jones RSP, Roberts J, Crane RS, et al. Mixed experiences of a mindfulness-informed intervention: Voices from people with intellectual disabilities, their supporters, and therapists. Mindfulness. 2019; 10(9): 1828-1841. [Link]

33. Kabat-Zinn J. Full catastrophe living how to cope with stress, pain and illness using mindfulness meditation. Piatkus; 2013. [Link]

34. Hollis-Walker L, Colosimo K. Mindfulness, selfcompassion, and happiness in non-meditators: A theoretical and empirical examination. Pers Individ Dif. 2011; 50(2): 222-227. [Link]

35. Safikhani F, Eftekhar Saadi Z, Naderi F, Marashian FS. The effectiveness of cognitive therapy based on conscious and mental imagery grammatical on spirituality and emotional processing of mothers of students with Autism Spectrum Disorder. Educational Development of Judishapur. 2020; 11(3): 427-445. [Persian]. Doi: 10.22118/edc.2020.241127.1470 [Link]

36. Ahmadi T, Kheirati H, Ghobari Bonab B. Effectiveness of mindfulness-based training on cognitive emotion regulation and cognitive flexibility in mothers of children with Learning Disabilities. Empowering Exceptional Children. 2019; 10(3): 125138. [Persian]. Doi: 10.22034/ceciranj. 2020. 167363. 1124 [Link]

37. Ghasemipour Y, Roshan B. Investigating the relationship between mindfulness and social support with mental health of mothers with Mentally Retarded child. J Child Ment Health. 2019; 6(1): 176-187. [Persian]. Doi: 10.29252/jcmh.6.1.15 [Link]

38. Lo HHM, Wong SWL, Wong JYH, Yeung JWK, Snel E, Wong SYS. The effects of family-based mindfulness intervention on ADHD symptomology in young children and their parents: A randomized control trial. J Atten Disord. 2020; 24(5): 667-680. Doi: 10.1177/1087054717743330 [Link]

39. Potharst ES, Leyland A, Colonnesi C, Veringa IK, Salvadori EA, Jakschik M, et al. Does mothers' selfreported mindful parenting relate to the observed quality of parenting behavior and mother-child interaction? Mindfulness (N Y). 2020; 1-13. Doi: 10. 1007/s12671-020-01533-0 [Link]

40. Tumminia MJ, Colaianne BA, Roeser RW, Galla BM. How is mindfulness linked to negative and positive 
affect? Rumination as an explanatory process in a prospective longitudinal study of adolescents. J Youth Adolesc. 2020; 49(10): 2136-2148. Doi: 10.1007/ s10964-020-01238-6 [Link]

41. Manzomeh S, Akbari B. Comparison of the effect of mindfulness-based cognitive therapy (MBCT) and progressive muscle relaxation (PMR) on general health indicators in the mothers of children with Leukemia. J Child Ment Health. 2019; 6(2): 13-26. [Persian]. Doi: 10.29252/ J Child Ment Health.6.2.3 [Link]

42. Aghdasi N, Soleimanian AA, Asadi Gandomani R. The effectiveness of mindfulness training on emotional schemas mothers of children with Cerebral Palsy. Archives of Rehabilitation. 2019; 20(1): 86-97. [Persian]. Doi: 10.32598/rj.20.1.86 [Link]

43. Khaleghipour S, Zargar F. Effect of mindfulnessbased cognitive therapy on depression and life expectancy mentally retarded children. Journal of Research in Behavioural Sciences. 2014; 12(2): 264273. [Persian]. [Link]

44. Mani A, Khabir L, Mousavinasab S, Ghanizadeh A. Effectiveness of group stress reduction on mental health, mothers' quality of life, and behavioral problems in children with attention deficit hyperactivity disorder. International Journal of School Health. 2020; 7(3): 6-14. Doi: 10.30476/ intjsh. 2020. 86373.1081 [Link]

45. Singh NN, Lancioni GE, Karazsia BT, Myers RE, Hwang Y-S, Anālayo B. Effects of mindfulness-based positive behavior support (mbpbs) training are equally beneficial for mothers and their children with autism spectrum disorder or with intellectual disabilities. Front Psychol. 2019; 10: 385. Doi: 10.3389/fpsyg. 2019.00385 [Link]
46. Shokri A, Kazemi R, Narimani M, Taklavi S. Comparison of the effectiveness of mindfulness-based cognitive therapy and emotion regulation training on parental stress of mothers with aggressive children. $\mathbf{J}$ Child Ment Health. 2020; 7(1): 205-219. [Persian]. Doi: 10.29252/jcmh.7.1.18 [Link]

47. Beyrami M, Hashemi T, Bakhshi Pour A, MahmoudAlilo M, Eghbali A. Comparison of the effect of two methods of emotion regulation training and mindfulness-based cognitive therapy on psychological distress and cognitive emotion regulation strategies of mothers of mentally retarded children. Journal of Modern Psychological Researches (Psychology). 2014; 9(33): 43-59. [Persian]. [Link]

48. Gershy N, Gray SAO. Parental emotion regulation and mentalization in families of children with ADHD. J Atten Disord. 2020; 24(14): 2084-2099. Doi: 10. 1177/1087054718762486 [Link]

49. Treynor W, Gonzalez R, Nolen-Hoeksema S. Rumination reconsidered: A psychometric analysis. Cognit Ther Res. 2003; 27(3): 247-259. [Link]

50. Yousefi Z, Abedi MR, Bahrami F, Mehrabi HA. Validation, factor structure, reliability and standardization of rumination inventory. Journal of Psychology. 2009; 13(149): 54-68. [Persian]. [Link]

51. Gross JJ. Emotion regulation: Affective, cognitive, and social consequences. Psychophysiology. 2002; 39(3): 281-291. [Link]

52. Asgari M, Matini A. The effectiveness of emotion regulation training based on gross model in reducing impulsivity in smokers. Counseling Culture and Psycotherapy. 2020; 11(42): 205-230. [Persian]. Doi: 10.22054/qccpc.2020.45707.2197 [Link] 